\title{
The Mean Age of Mantle and Crustal Reservoirs
}

\author{
STEIN B. JACOBSEN AND G. J. WASSERbURG \\ The Lunatic Asylum of the Charles Arms Laboratory, Division of Geological and Planetary Sciences \\ California Institute of Technology, Pasadena, Califormia 91125
}

\begin{abstract}
Mantle and crust evolution is discussed in terms of two simple transport models. In model I, continents $(j=3)$ are derived by melt extraction over the history of the earth from undepleted mantle $(j=1)$, and the residue forms a depleted mantle $(j=2)$, which today is the source of mid-ocean ridge basalts. In model II, new additions to continents are derived from a mantle reservoir 2 , which becomes more depleted through time by repeated extraction of melts. Transport equations were solved for stable $s$, radioactive $r$, and daughter $d$ isotopes for arbitrary mass growth curves $M(\tau)$. For both models the isotopic composition and concentrations of trace elements are shown to reduce to simple mathematical expressions which readily permit calculations of basic evolutionary parameters from the data. For longlived isotopes $\left(\lambda^{-1} \gg 4.5\right.$ aeons) for model $I$ the deviations in parts in $10^{4}$ of the ratio of a daughter isotope to a stable reference isotope of the same element in reservoirs $j=2,3$ from that of 1 is given by $\varepsilon_{d j}{ }^{*}=$ $Q_{d}{ }^{+} \bar{t}_{M, j} f_{j}^{\prime s}$. Here $\bar{t}_{M, j}$ is the mean age of the mass of $j, f_{j}^{r / s}$ is the enrichment factor of the ratio of a radioactive isotope to a stable isotope relative to that in 1 , and $Q_{d}{ }^{*} \simeq$ const. Thus for long-lived isotopes such as ${ }^{147} \mathrm{Sm}$ and ${ }^{87} \mathrm{Rb}$ the only time information that can be obtained from model $I$ from measurement of the relative chemical enrichment factors and isotopic ratios at a single time is the mean age of the mass of the continental crust and the complementary depleted mantle reservoir. This mean age is independent of the long-lived parent-daughter system. An analogous result is obtained for model II, where $\epsilon_{d, 2}{ }^{*}=Q_{d}{ }^{*}$ $\left\langle f_{2}^{r / s}\right) \tau$. Here $\left\langle f_{2}^{r / s}\right\rangle$ is the weighted time average of the enrichment factor, and $\tau$ is the time measured from the origin of the earth. The mean age of the mass of the crust $\left(\bar{t}_{M, 3}\right)$ and the time parameter $\bar{t}_{r / s}=$ $\tau\left(f_{2}^{r / s}\right\rangle / f_{2}^{r / s}$ for the crust in model II will for long-lived parent-daughter systems be different depending on the element fractionation during partial melting. Decay systems with small parent-daughter fractionations during partial melting may, however, be used to estimate the mean age of the continental crust. SmNd and Rb-Sr isotopic data for continental crust, depleted and undepleted mantle, have been used to evaluate both models and yield young mean ages for the mass of the continental crust of 1.8 and 1.5 aeons for model I and model II, respectively. Both models also suggest that the rate of growth of the continents for the last 0.5 aeon is much less than the average growth rate. The young mean age of the continents implies either rapid refluxing of crustal materials to the mantle in the period from 4.5 to 3.6 aeons or that very little early crust ever formed. Mass balance calculations for both models show that the continents were only formed from $\sim 30 \%$ of the total mantle, leaving $70 \%$ of the mantle as undepleted. The major difference in the two models lies in the difference in the compositions of newly derived crust. For model I the trace element concentrations in new additions to the crust is constant, and the isotopic values are those of the undepleted mantle reservoir, in agreement with recent $\mathrm{Nd}$ isotopic studies. The correlation line between $\epsilon_{\mathrm{Nd}}$ and $\epsilon_{\mathrm{Sr}}$ for young basalts can be explained with model I by mixing depleted and undepleted mantle, but it cannot in any simple way be explained by model II. Model II implies that new additions to the continents have the isotopic characteristics of depleted mantle and that the concentration of $\mathrm{Rb}, \mathrm{U}, \mathrm{Ba}$, and other highly incompatible trace elements in newly added material have changed by a factor of $\sim 10$ through time, for which there is no evidence. For both models the simple analytical expressions derived herein permit calculations of earth models with great facility without requiring a computer calculation.
\end{abstract}

\section{INTRODUCTION}

Over the past few years a substantial amount of new data has become available on the $\mathrm{Sm}-\mathrm{Nd}$ and $\mathrm{Rb}-\mathrm{Sr}$ isotope characteristics of mantle and crustal reservoirs. These data have been used to determine the times of additions of new continental crustal materials [McCulloch and Wasserburg, 1978] and in discussions of the evolution of the mantle sources of modern continental and oceanic basalts. These studies have demonstrated that the mid-ocean ridge basalts (MORB) have been derived from a depleted mantle source [DePaolo and Wasserburg, 1976a, b; Richard et al., 1976] and that young continental flood basalts and new additions to the continents throughout most of the earth's history appear mainly to have been derived from undepleted mantle reservoirs [DePaolo and Wasserburg, 1976b, 1979b]. Recently, data on the initial isotopic composition of 0.5 -aeon-old ( 1 aeon $=1 \mathrm{AE}=10^{9}$ years) oceanic crust have become available which permit an estimate of the composition of the oceanic mantle in the early paleozoic [Jacobsen and Wasserburg, 1979]. The simplest model for explaining the observed isotopic heterogeneities in the mantle

Copyright $(\mathcal{C} 1979$ by the American Geophysical Union.

Paper number 9B1 199.

0148-0227/79/009B-1190\$01.00 would be to assume that they formed in a single event [Brooks et al., 1976a, b; Brooks and Hart, 1978]. However, as was discussed by O'Nions et al. [1978], Tatsumoto [1978], and Jacobsen and Wasserburg [1979], available $\mathrm{Pb}, \mathrm{Nd}$, and $\mathrm{Sr}$ isotopic data on young basalts do not appear to fit such a single-stage model, and it is not compatible with our knowledge that the continental crust has evolved in many stages over geologic time [see, for example, Moorbath, 1978; O'Nions and Pankhurst, 1978; McCulloch and Wasserburg, 1978]. Because of these considerations it is necessary to analyze the data in terms of continuous or multiepisodic mantle-crust transport models.

In this study we present an analysis of two simple transport models for trace elements and relate them to the isotopic abundance patterns that can be observed. The general transport equations for transfer of stable, radioactive, and daughter isotopes between $n$ reservoirs were given by Wasserburg [1964]. The models presented here assume that the transport is solely from mantle to continental crust and do not treat the flux back to the mantle of continental crustal material for simplicity, but the treatment may be simply extended to include this. In the first model (model I) the mechanism for crustal 
growth is by deriving melts over the age of the earth by equilibrium partial melting from undepleted mantle. In the second model (model II), melts that form new continental crust are being derived from a mantle reservoir that is continuously depleted through time. We will show that although the models involve rather heavy algebra, they lead to exceedingly simple expressions for the isotopic ratios and trace element abundances in terms of the mass of continental crust and depleted mantle which are evolved. The models apply to arbitrary crustal growth rates in contrast to previous transport models [Patterson, 1964; Patterson and Tatsumoto, 1964; Wasserburg, 1966; Armstrong, 1968; Hart and Brooks, 1970; Russell, 1972; Russell and Birnie, 1974; DePaolo, 1978; O'Nions et al., 1979]. This approach is a generalization of the treatment of nucleosynthetic time scales given by Schramm and Wasserburg [1970]. The results may be used directly to discuss earth models using available isotopic data and concentration data for mantle and crustal rocks. This treatment appears to give a deep and direct insight into the problems of mantle evolution.

\section{Mantle-Crust Transport Models}

\section{Model I}

We first consider a model of crustal growth from an undifferentiated mantle reservoir (reservoir 1 ) with a given segment of the mantle being differentiated to form two reservoirs: a depleted mantle (reservoir 2) and a continental crust (reservoir 3). The model is shown schematically in Figure 1. We define $M_{j}, N_{i, j}$ and $C_{i j}$ to be the total mass of reservoir $j$, number of atoms of species $i$ in reservoir $j$, and the concentration of species $i$ in reservoir $j$, respectively. Differential masses added to or subtracted from the total reservoir $j$ are denoted by $\delta M_{j}$. The number of species $i$ and the concentration of $i$ in the differential mass $\delta M_{j}$ are denoted by $\delta N_{i, j}$ and $c_{i, j}$ respectively. Let us assume that a mass $\delta M_{1}$ is removed from reservoir 1 and a partially melted fraction $F$ is extracted from this differential mass to form new crust with added mass $\delta M_{3}$ and a new residual mass $\delta M_{2}$ is added to the depleted mantle. This gives $\delta M_{3} / \delta M_{1}=F$ and $\delta M_{2} / \delta M_{\mathrm{i}}=1-F$. We imagine that the crust is thus increased by the amount $\delta M_{3}$ and the undifferentiated mantle reservoir is diminished in amount by mass $\delta M_{1}$. The mass $\delta M_{2}$ is added to the depleted mantle, which we assume to be otherwise isolated from the remaining undifferentiated reservoir 1 .

The number of atoms of species $i$ in each differential mass $j$ in this unit process is $\delta N_{l,}$, which gives

$$
\delta N_{1,1}=\delta N_{i, 2}+\delta N_{1,3}
$$

The number of species $i$ in the differential mass $\delta M$, may be written $\delta N_{t_{v}}=c_{t,} \delta M_{\jmath}$. Conservation of species and mass gives

$$
c_{t, 1}=c_{t, 2}(1-F)+c_{t, 3} F
$$

Trace elements are fractionated between melts and residue with an effective partition coefficient. The effective partition coefficient $D$, for element $i$ between the residue $\left(\delta M_{2}\right)$ and the partial melt $\left(\delta M_{3}\right)$ is defined by $D_{1} \equiv c_{t, 2} / c_{i, 3}$. The concentration in $\delta M_{3}$ is

$$
c_{i, 3}=\frac{c_{i, 1}}{F+D_{i}(1-F)}=\frac{c_{t, 2}}{D_{i}}
$$

We may thus express the number of species $i$ in the differential masses $j$ in terms of their masses $\delta M_{j}$ and the concentration in reservoir $\mathrm{l}$, since $c_{i, 1}=C_{i, 1}$ :

$$
\begin{array}{rl}
\delta N_{i,}=\frac{D_{i, j} C_{i, 1}}{F+D_{(}(1-F)} \delta & \\
& \\
D_{i, j}=D_{i} & j=2 \\
D_{i,}=1 & j=3
\end{array}
$$

We consider the following species: (1) a stable index isotope $s$ of an element which is not affected by radioactive decay, (2) a radioactive isotope $r$ with decay constant $\lambda$, and (3) a daughter isotope $d$ which is the decay product of $r$ and of the same chemical element as $s$.

The transport equations for the total reservoir $j$ containing the number $N_{\iota}$ of each isotope $i=s, r, d$ are

$$
\begin{array}{rl}
\frac{d N_{i, j}(\tau)}{d \tau}=\frac{\delta N_{i, j}}{\delta \tau}-\lambda_{i} N_{r,}(\tau) & \\
\lambda_{i}=0 & i=s \\
\lambda_{i}=\lambda & i=r \\
\lambda_{i}=-\lambda & i=d
\end{array}
$$

where $d N_{i, j} / d \tau$ is the time derivative and $\delta N_{i,} / \delta \tau$ is the flux of species $i$ into reservoir $j$. In this treatment, $\delta \tau$ is the time over which mass $\delta M_{1}$ is differentiated at time $\tau$. For simplicity we have chosen to ignore transport between 2 and 3 . Using the expressions for $\delta N_{t,}$ in terms of $C_{i, 1}$ and $\delta M_{j}$ and calling $\delta M_{j} /$ $\delta \tau \equiv M_{j}^{\prime}(\tau)$, which is the rate of mass growth of reservoir $j$, we obtain the basic transport equation for model $I$,

$$
\frac{d N_{i, \gamma}}{d \tau}=\frac{D_{i, j} C_{i, 1}(\tau)}{F+D_{l}(1-F)} M_{j}^{\prime}(\tau)-\lambda_{i} N_{r, \mathcal{N}}(\tau)
$$

where $D_{i j}$ and $\lambda_{i}$ are defined as in (4) and (5). The first term on the right-hand side of (6) is the transport term, and the second term is due to either radioactive decay or production.

The general solution of (6) for a stable index isotope is

$$
N_{s,}(\tau)=\frac{D_{s,}}{F+D_{s}(1-F)} \int_{0}^{\tau} C_{s, 1}(\xi) M_{j}^{\prime}(\xi) d \xi
$$

The equation was integrated with the assumption that the time $\tau=0$ at the time of initial chemical differentiation of the earth and $N_{s_{1}}(0)=0$. The earth is taken to be initially homogeneous.

The undifferentiated reservoir is characterized by a closed system behavior for intensive quantities, so that the concentration for species $s, r$, and $d$ are

$$
\begin{gathered}
C_{s, 1}(\tau)=C_{s, 1}(0) \\
C_{r, 1}(\tau)=C_{r, 1}(0) e^{-\lambda \tau} \\
C_{d, 1}(\tau)=C_{d, 1}(0)+C_{r, 1}(0)\left[1-e^{-\lambda \tau}\right]
\end{gathered}
$$

The relationship between the masses of reservoirs 2 and 3 is given by $M_{3}(\tau)=[F /(1-F)] M_{2}(\tau)$. Substituting (8) into (7) gives the following general solutions for stable isotopes in reservoirs 2 and 3 .

$$
\begin{aligned}
& N_{s, 2}(\tau)=\frac{D_{s} C_{s, 1}(0)}{F+D_{s}(1-F)} M_{2}(\tau) \\
& N_{s, 3}(\tau)=\frac{C_{s, 1}(0)}{F+D_{s}(1-F)} M_{3}(\tau)
\end{aligned}
$$

The above equation for a stable isotope in the crust may also be written as $C_{s, 3}(\tau)=C_{s, 1}(0) /\left[F+D_{s}(1-F)\right]$, which is equivalent to the equation for equilibrium partial melting derived by Consolmagno and Drake [1976] which showed that previous equations given by Shaw [1970], Schilling [1971], and $O$ 'Nions and Clarke [1972] all reduce to this general form. 


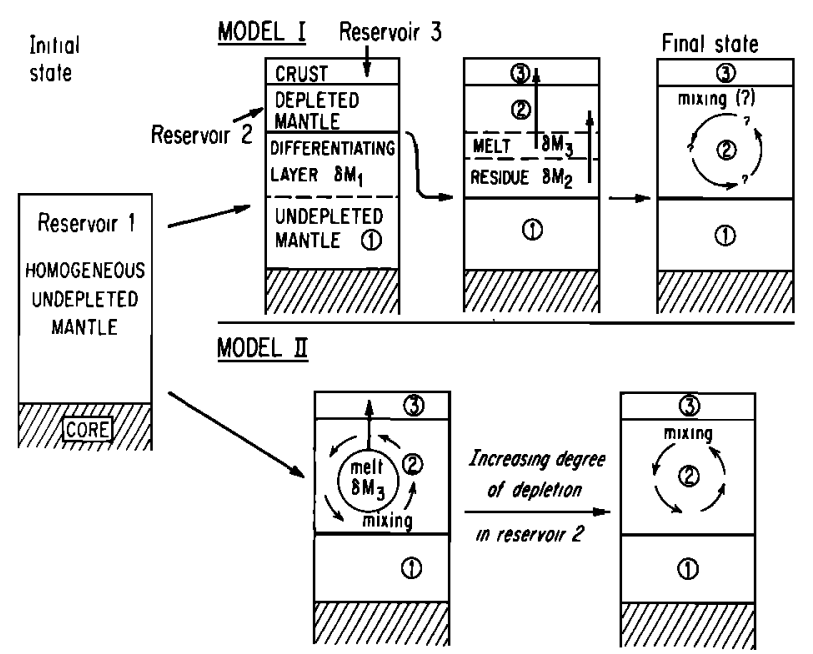

Fig. 1. Cartoon showing the processes in model I and model II. Model I is a three-layer model consisting of undepleted mantle (1), depleted mantle (2), and continental crust (1), as indicated under the final state. In model $I$ a given segment (the differentiating layer $\delta M_{1}$ ) of undepleted mantle $(1)$ is being differentiated by equilibrium partial melting and added to two reservoirs: a depleted mantle (2) and a continental crust (3). We assume that a differential mass $\delta M_{1}$ is removed from reservoir 1 and a partially melted fraction $F$ is extracted from this differential mass to form new crust with added mass $\delta M_{3}$ and that a new residual mass $\delta M_{2}$ is added to the depleted mantle. In this differentiation process the masses of reservoirs 1,2 , and 3 are conserved. The masses of the depleted mantle and the crust increase with time, and the undepleted mantle decreases with time. The upper boundary of the undepleted mantle is thus lowered, and the volumes of both depleted mantle and crust increased. These stages are shown in the second and third columns. In model II the crust grows from an initially undifferentiated mantle reservoir (2), which is depleted at all times subsequent to the initial chemical differentiation as a result of continuing crustal growth. This reservoir may make up all or part of the mantle. Layers 2 and 3 are thus the only active regions in this model. The remaining undifferentiated mantle is passive and is still indicated as layer 1 . In this model we assume that a differential mass $\delta M^{*}$ of reservoir 2 is being differentiated into a melt $\delta M_{3}$, which is added to the continental crust and a residue $\delta M_{R}{ }^{*}$. The degree of melting $F$ is taken as finite. The residue after removal of a melt fraction from reservoir 2 is assumed to be homogenized instantaneously with the remaining part of the depleted mantle. The total mass of reservoirs 2 and 3 is conserved; the continental crust increases in mass with time, and the depleted mantle decreases in mass with time. In both models the depleted mantle is taken to include the basaltic part of the oceanic crust, since it is derived from the depleted mantle and is subducted back to the depleted mantle at a short time scale $(<0.2$ aeon).

Solutions of (6) analogous to (7) may also be obtained for radioactive isotopes. Substituting (9) into these gives the following result for reservoirs 2 and 3 :

$$
\begin{aligned}
& N_{r, 2}(\tau)=\frac{D_{r} e^{-\lambda \tau} C_{r, 1}(0)}{F+D_{r}(1-F)} M_{2}(\tau) \\
& N_{r, 3}(\tau)=\frac{e^{-\lambda \tau} C_{r, 1}(0)}{F+D_{r}(1-F)} M_{3}(\tau)
\end{aligned}
$$

Similarly, by substituting (10), (13), and (14) into (6) we obtain the following equations for daughter isotopes in reservoirs 2 and 3:

$$
\begin{aligned}
N_{d, 2}(\tau)= & \left\{D _ { d } \left[C_{d, 1}(\tau) M_{2}(\tau)+\lambda C_{r, 1}(0)\right.\right. \\
& {\left[\frac{F+D_{d}(1-F)}{F+D_{r}(1-F)}\left(\frac{D_{r}}{D_{d}}\right)-1\right] } \\
& \left.\left.\int_{0}^{\tau} M_{2}(\xi) \exp [-\lambda \xi] d \xi\right)\right]\left[F+D_{d}(1-F)\right]^{-1}
\end{aligned}
$$

$$
\begin{array}{r}
N_{d, 3}(\tau)=\left\{C_{d, 1}(\tau) M_{3}(\tau)+\lambda C_{r, 1}(0)\left[\frac{F+D_{d}(1-F)}{F+D_{r}(1-F)}-1\right]\right. \\
\left.\int_{0}^{\tau} M_{3}(\xi) \exp [-\lambda \xi] d \xi\right\}\left[F+D_{d}(1-F)\right]^{-1}
\end{array}
$$

where $D_{s}=D_{d}$, since $d$ and $s$ are isotopes of the same element, and $C_{d, 1}(\tau)$ is given by $(10)$.

The enrichment factor of the ratio of a radioactive isotope to a stable isotope in a reservoir $j$ relative to that in reservoir 1 is called $f_{j}^{r / s}$. This enrichment factor is the same both for new additions to $j$ and for the total reservoir $j$, and it is defined by

$$
f_{j}^{r / s} \equiv \frac{N_{r, j}(\tau) / N_{s, j}(\tau)}{N_{r, 1}(\tau) / N_{s, 1}(\tau)}-1
$$

For this model the enrichment factor is independent of time and is given by

$$
f_{2}^{r / s}+1=\left(\frac{D_{r}}{D_{s}}\right) \frac{F+D_{s}(1-F)}{F+D_{r}(1-F)}=\left(\frac{D_{r}}{D_{s}}\right)\left(f_{3}^{r / s}+1\right)
$$

As $D_{s}=D_{\phi}$ the ratio of a daughter isotope to a stable reference isotope of the same element (with no parent) in each reservoir is given by

$$
\begin{aligned}
\frac{N_{d, \gamma}(\tau)}{N_{s, \gamma}(\tau)}=\frac{N_{d, 1}(\tau)}{N_{s, 1}(\tau)}+\frac{N_{r, 1}(\tau)}{N_{s, 1}(\tau)} \frac{\int_{j}^{r / s} \lambda}{M(\tau)} & \\
& \cdot \int_{0}^{\tau} M_{\mathcal{N}}(\xi) \exp [\lambda(\tau-\xi)] d \xi
\end{aligned}
$$

In terms of deviations $\epsilon_{d_{l}}{ }^{*}(\tau)$ in parts in $10^{4}$ from the ratios in the undifferentiated reference reservoir we obtain the final equations to be used in calculations for this model for arbitrary rates of growth of the crust and mantle:

$$
\epsilon_{d_{\nu}}{ }^{*}(\tau)=\frac{Q_{d}{ }^{*}(\tau) f_{j}^{r / s}}{M_{j}(\tau)} \int_{0}^{\tau} M_{j}(\xi) \exp [\lambda(\tau-\xi)] d \xi
$$

and

$$
\frac{\epsilon_{d, 3}^{*}(\tau)}{\epsilon_{d, 2}^{*}(\tau)}=\frac{f_{3}{ }^{r / s}}{f_{2}{ }^{r / s}}
$$

where

$$
Q_{d}^{*}(\tau) \equiv\left[10^{4} \lambda\left(\frac{N_{r, 1}(\tau)}{N_{s, 1}(\tau)}\right)\right] /\left(\frac{N_{d, 1}(\tau)}{N_{s, 1}(\tau)}\right)
$$

The time parameter $\tau$ is the time running forward from the initial state (cf. equation (7)), and the time measured backward from the present will as usual be called $T$ (see Figure 2). Here $\epsilon_{d_{y}}{ }^{*}(\tau)=\epsilon_{d_{y}}{ }^{*}\left(T_{0}-T\right) \equiv \epsilon_{d, j}(T)$, where $T=T_{0}-\tau, T_{0}$ is the age of the earth today, and $\epsilon_{d,}(T)$ corresponds to $\epsilon_{\mathrm{Nd}}$ and $\epsilon_{\mathrm{Sr}}$ as defined by DePaolo and Wasserburg [1976a, 1977]. The asterisks denote the functional form of the deviations ' $\epsilon$ ' relative to a time variable with an origin at the time of formation of the earth. Similarly, we define $Q_{d}{ }^{*}(\tau)=Q_{d}{ }^{*}\left(T_{0}-T\right) \equiv Q_{d}(T)$ and note that $Q_{d}(0)$ is equal to the constants $Q_{\mathrm{Nd}}$ and $Q_{\mathrm{sr}}$ used by DePaolo and Wasserburg [1976a, 1979a] for the Sm/Nd and $\mathrm{Rb} / \mathrm{Sr}$ systems, respectively. If $\lambda \tau \ll 1$, then we have a good approximation that $Q_{d}^{*}(\tau)=Q_{d}(0)$. We note that the 


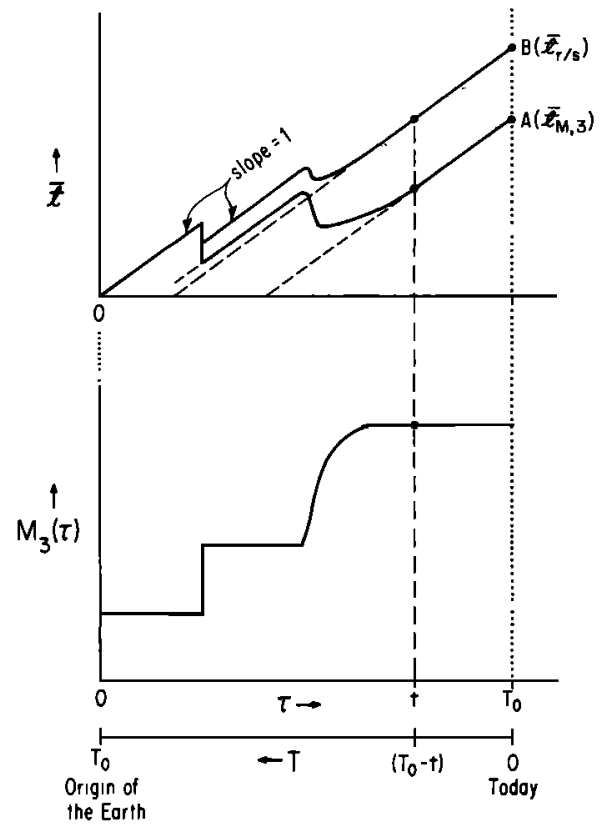

Fig. 2. Cartoon showing the relationship between a mean age $t$ and the corresponding mass growth curve $M_{3}(\tau)$ for the crust. Two time variables are shown, where $\tau$ is the time measured from the origin of the earth and $T$ is the time measured backward from today. The vertical dashed line is shown for a time $\tau=t$ years after the origin of the earth, which corresponds to a time $T_{0}-t$ years ago. Curve $A$ shows the mean age of the mass of the crust $I_{M, 3}$ versus time $\tau$. The breaks in curve A correspond to the breaks in $M_{3}(\tau)$. Rapid addition of new material implies a rapid decrease in $\boldsymbol{t}_{M, 3}$ of the continental crust. For periods where no, significant new mass is added, $(d t / d \tau)=1$. This is valid for any model. For models such as model $l$, where the concentration of stable isotopes does not vary with time, $t_{M, 3}$ is also the mean age of any stable isotope $t_{s, 3}$ in the crust. For parent-daughter systems with $\lambda_{\tau} \ll 1, t_{M, 3}$ is also the mean age of the parent and daughter isotopes in the crust (i.e., $\bar{t}_{M, 3}=t_{d, 3}=t_{r, 3}$ ). Curve B shows the case where a stable isotope is strongly enriched in the crust earlier in time and the concentration in the bulk crust decreases monotonically with time. This weights the older material more strongly and raises the value of $i_{s, 3}$ above $I_{M, 3}$ (curve A). The curve $t_{s, 3}$ for model II has a more subdued behavior compared with model I for more recent additions. Similarly, if a long-lived parent is much more strongly enriched than the daughter in the crust, then the factor $I_{r / s}$ shows a behavior like that of curve B. Subsequent to $\tau=\mathrm{t}$ no mass is added, so $(d \bar{t} / d \tau)=1$ for both curves for the time interval $\tau=t$ to $\tau=T_{0}$. The difference between the two curves is given by (66).

values of $\epsilon_{d,}{ }^{*}$ are the average values in each reservoir. Insofar as each new added segment was isolated, the added segment would follow its own evolutionary path governed by its initial state. This model has the property that new crustal and new mantle material would at the time of addition have the isotopic values of the undifferentiated reservoir 1. Magmas derived from subsequent melting of the crust or the depleted mantle would have distinctive characteristics at a given time. For a constant rate of crustal growth, (20a) takes the following form:

$$
\epsilon_{d,}^{*}(\tau)=\frac{Q_{d}^{*}(\tau) f_{j}^{r / s}}{\lambda}\left[\frac{e^{\lambda \tau}-1}{\lambda \tau}-1\right]
$$

and if $\lambda \tau \ll 1$, this equation reduces to

$$
\epsilon_{d,}{ }^{*}(\tau)=Q_{d}^{*} f_{j}^{r / s}(\tau / 2)
$$

The average time of residence $(\bar{t})$ of a stable atom $s$, which is not produced by radioactive decay, in reservoir $j(j=2$ or 3 ) at a time $\tau$ is, using (11) and (12),

$$
\begin{aligned}
& \bar{t}_{s, j} \equiv\left\langle(\tau-\xi) \delta N_{s, j}(\xi) / N_{s,}(\tau)\right\rangle=\frac{1}{N_{s,}(\tau)} \int_{0}^{\tau}(\tau-\xi)\left(\frac{\delta N_{s,}}{\delta \xi}\right) d \xi \\
& =\frac{1}{M_{\mathcal{N}}(\tau)} \int_{0}^{\tau}(\tau-\xi) M_{j}^{\prime}(\xi) d \xi=\frac{1}{M_{\mathcal{N}}(\tau)} \int_{0}^{\tau} M_{\mathcal{N}}(\xi) d \xi
\end{aligned}
$$

We have here assumed that there was initially no crust or depleted mantle, so that $N_{s,}(0)=M_{\mathcal{C}}(0)=0$. Expression (22) is equivalent to the average age as measured today of continental crustal material if $\tau=T_{0}$, the age of the earth, otherwise it is the average age as measured $T=T_{0}-\tau$ years ago. Note that for this model, $\bar{t}_{s, j}$ is the same as the average age of the crust or depleted mantle and is independent of the species or of the reservoir. We may therefore drop the subscripts on $\bar{t}$ for this model.

Defining

$$
\begin{aligned}
\left\langle t^{n}\right\rangle \equiv \frac{1}{M(\tau)} \int_{0}^{\tau}(\tau-\xi)^{n} & \left(\frac{d M_{j}}{d \xi}\right) d \xi \\
& =\frac{n}{M_{\mathcal{N}}(\tau)} \int_{0}^{\tau}(\tau-\xi)^{n-1} M_{\mathcal{N}}(\xi) d \xi
\end{aligned}
$$

where $n$ is an integer, then the integral in (20) can be written in the following form:

$$
\begin{aligned}
I_{(}(\tau) & \equiv \frac{1}{M_{\mathcal{N}}(\tau)} \int_{0}^{\tau} M_{\mathcal{N}}(\xi) \exp [\lambda(\tau-\xi)] d \xi \\
& =\frac{1}{M_{\mathcal{N}}(\tau)} \int_{0}^{\tau} \sum_{n=0}^{\infty} \frac{\lambda^{n}}{n !}(\tau-\xi)^{n} M_{\mathcal{N}}(\xi) d \xi=\sum_{n=1}^{\infty} \frac{\lambda^{n-1}}{n !}\left(t^{n}\right\rangle
\end{aligned}
$$

Then we have from (20)

$$
\begin{aligned}
\epsilon_{d, j}{ }^{*}(\tau) & =Q_{d}^{*}(\tau) f_{j}^{r / s} \sum_{n=1}^{\infty} \frac{\lambda^{n-1}}{n !}(t) \\
& =Q_{d}^{*}(\tau) f_{j}^{r / s}\left\langle t^{1}\right\rangle\left[1+\frac{\lambda\left\langle t^{2}\right\rangle}{2\left(t^{1}\right\rangle}+\frac{\lambda^{2}\left\langle t^{3}\right\rangle}{6\left\langle t^{1}\right\rangle}+\cdots\right]
\end{aligned}
$$

We note that for long-lived isotopes with $\lambda \tau \ll 1$ we get, to a good approximation,

$$
\epsilon_{d j}^{*}(\tau)=Q_{d}^{*}(\tau) f_{j}^{r / s} \bar{t}
$$

or

$$
\epsilon_{d v}(T)=Q_{d}(T) f_{i}^{r / s} \bar{t}
$$

as $\bar{t}=\left\langle t^{1}\right\rangle$.

If we can measure $\epsilon_{d,}{ }^{*}(\tau)$ and $f_{f}^{r / s}$ for a very long lived isotope at $T=T_{0}-\tau$ years ago, then the only information we can obtain is the mean age of reservoir $j$ as measured $T=T_{0}$ $-\tau$ years ago. The resulting mean age is independent of which very long lived species is used. This is independent of the rate of growth of the mass of reservoir $j$ or the rate of transport of species $i$. This general treatment gives an integral which resembles a Laplace transform of $M_{\mathcal{N}}(\tau)$ with a transform variable $\lambda$. This would permit a unique inversion for $M_{(}(\tau)$ if the transform was known for all values of $\lambda$. Insofar as 
TABLE 1. Values of $I_{j}(\tau)$ at $\tau=4.55$ Aeons for Various ParentDaughter Systems for a Constant Rate of Crustal Growth With a Mean Age of $\bar{t}=2.275$ Aeons

\begin{tabular}{|c|c|c|}
\hline Radioactive Parent & Decay Constant, aeons ${ }^{-1}$ & $I_{\mathcal{N}}(\tau)$, aeons \\
\hline$\ldots$ & 0 & 2.275 \\
\hline${ }^{147} \mathrm{Sm}$ & 0.00654 & 2.30 \\
\hline${ }^{87} \mathbf{R b}$ & 0.0142 & 2.32 \\
\hline${ }^{187} \mathbf{R e}$ & 0.0161 & 2.33 \\
\hline${ }^{176} \mathrm{Lu}$ & 0.0198 & 2.34 \\
\hline${ }^{232} \mathrm{Th}$ & 0.049475 & 2.45 \\
\hline${ }^{238} \mathrm{U}$ & 0.155125 & 2.92 \\
\hline${ }^{40} \mathbf{K}$ & 0.5543 & 6.39 \\
\hline${ }^{235} \mathrm{U}$ & 0.98485 & 18.77 \\
\hline${ }^{244} \mathrm{Pu}$ & 8.48 & $1.44 \times 10^{13}$ \\
\hline
\end{tabular}

there is only a limited number of decay schemes a unique inversion is not possible, although a substantial amount of information may be deduced. We have calculated $I /(\tau)$ for a constant rate of crustal growth for various parent-daughter systems (Table 1) for $\tau=4.55$ aeons and thus a mean age of the mass of $j$ of 2.275 aeons. The isotopes ${ }^{147} \mathrm{Sm},{ }^{87} \mathrm{Rb},{ }^{187} \mathrm{Re}$, ${ }^{176} \mathrm{Lu}$, and ${ }^{232} \mathrm{Th}$ all have mean lives that are sufficiently long so that $I_{\mathcal{H}}(\tau) \approx \bar{t}$ as shown in Table 1 . The concordant results obtained by Jacobsen and Wasserburg [1979] for Rb-Sr and Sm-Nd single-stage ages for the oceanic mantle clearly do not represent a unique time event but an average age and the concordance for model $I$ is a consequence of the long mean lives of both ${ }^{147} \mathrm{Sm}$ and ${ }^{87} \mathrm{Rb}$. Inspection of Table 1 shows that ${ }^{238} \mathrm{U}$ has a significant deviation from the case with $\lambda=0$, and ${ }^{40} \mathrm{~K}$ and ${ }^{235} U$ are greatly different from this case. These species have sufficiently short mean lives that the higher-order terms become important, and the equations are no longer redundant. From this result it is clear that the detailed history of the early earth must be derived from the latter two decay schemes. These different decay schemes when taken together yield information on the detailed time evolution by measurement at a single point in time.

The mean age $\bar{t}$ shows the relationship

$$
\frac{d \bar{t}}{d \tau}=1-\frac{\bar{t}}{M}\left(\frac{d M}{d \tau}\right)=1-\bar{t}\left(\frac{d \ln M}{d \tau}\right)
$$

so that for $(d M / d \tau)>0,(d \bar{t} / d \tau)<1$. When $(d M / d \tau)=0$, it follows that $(d \bar{t} / d \tau)=1$. We also note that $(d \ln \bar{t} / d \tau) \geq-(d \ln$ $M / d \tau)$ and that $(d \bar{t} / d \tau) \leq 0$ if $(d \ln M / d \tau) \geq(1 / \bar{t})$. This is shown schematically in Figure 2. It follows from (27) that a similar relationship must hold for the $\epsilon$ value for all systems involving very long lived isotopes. If we know $\bar{t}$ as a function of time and the mass of the crust today, then we may calculate the mass of the continents as a function of time from the following equation:

$$
M_{3}(\tau)=M_{3}\left(T_{0}\right) \frac{\bar{t}\left(T_{0}\right)}{\bar{t}(\tau)} \exp \left[-\int_{\tau}^{T_{0}} \frac{d \xi}{\bar{t}(\xi)}\right]
$$

where $T_{0}$ is the age of the earth as measured today.

\section{Geometrical Constraints for Model I}

The mechanism for crustal growth in this model is by deriving melts from undepleted mantle. The mass transfer from a deep-seated undepleted reservoir may occur through rising blobs. At shallow levels in the mantle the blobs may intersect the solidus and be partially melted. However, only a fraction $\beta$ of the blobs may rise underneath the continental crust and contribute to crustal growth. The remaining fraction of the blobs $(1-\beta)$ rise underneath the oceanic crust and may contribute to oceanic volcanism. However, these may be mixed back into the mantle with a short time scale ( $<0.2$ eon) owing to the rapid turnover in the oceanic mantle implied by sea floor spreading and not become attached to the continents. This would correspond to adding undifferentiated mantle to the depleted mantle. The possiblity that undifferentiated mantle in this way gets mixed with depleted mantle may easily be incorporated in the equations for model I. We assume that a differential mass $\delta M_{1}$ is derived from reservoir 1 and adds a differential mass $\delta M_{0}^{*}$ to blobs underneath the oceans and $\delta M_{C} *$ to blobs rising underneath the continental crust. Then we have that $\delta M_{C}^{*} / \delta M_{1}=\beta$ and $\delta M_{0}^{*} / \delta M_{1}=1-\beta$, where $\beta$ is the probability that a mass taken from reservoir $l$ is directed toward a continental segment. The blobs underneath the continental crust are partially melted to a degree $F$ and thus the differential mass added to the crust is $\delta M_{3}=F \delta M_{C}{ }^{*}$, and the corresponding residue $R$ of $\delta M_{R}^{*}=(1-F) \delta M_{C}^{*}$ is left in the mantle and remixed. The blobs $\delta M_{0}^{*}$ which rise in the oceanic regions will also differentiate but are not isolated and are taken to be remixed consistent with the general scheme of model $I$. The contributions of $\delta M_{0}^{*}$ to reservoir 2 are thus not depleted. In this process a mass $\delta M_{2}=\delta M_{0}{ }^{*}+$ $\delta M_{R}{ }^{*}$ is added to reservoir 2 . Conservation of mass and species implies that the concentration of $i$ in the crust $c_{i, 3}$ is given by $C_{i, 1}=c_{1,3}\left[F+D_{i}(1-F)\right]$ as before (equation (3)). However, the relationship between the rates of growth of the crust and depleted mantle and the composition of the depleted mantle will be changed. The relationship between the masses of reservoirs 2 and 3 is given by

$$
M_{3}(\tau)=M_{2}(\tau)\left[\frac{\beta F}{1-\beta F}\right]
$$

In this case we have from mass and species conservation that $C_{t, 1}=c_{t, 3} \beta F+\bar{c}_{t, 2}(1-\beta F)$, where $\bar{c}_{t, 2}$ is the effective concentration in the total material added to layer 2 in masses $\delta M_{0}^{*}$ and $\delta M_{R}{ }^{*}$. The concentration of species $i$ in reservoir 2 is given by

$$
\frac{\bar{c}_{t, 2}}{C_{t, 1}}=\frac{F(1-\beta)+D_{i}(1-F)}{(1-F \beta)\left[F+D_{i}(1-F)\right]}
$$

where $\left(\tilde{c}_{i, 2} / C_{t, 1}\right)>D_{1} /\left[F+D_{i}(1-F)\right]$. This version of model I changes (3), (4), and (6) for reservoir 2 and gives $\left(\delta N_{t, 2} / \delta \tau\right)=$ $\tilde{c}_{i, 2}\left(\delta M_{2} / \delta \tau\right)$ in (5). All the equations for the continental crust will be the same as those derived previously. For reservoir 2 the transport equation corresponding to (6) is

$$
\frac{d N_{t, 2}}{d \tau}=\frac{\grave{F}(1-\beta)+D_{i}(1-F)}{(1-F \beta)\left[F+D_{i}(1-F)\right]} C_{i, 1}(\tau) M_{2}^{\prime}(\tau)-\lambda_{i} N_{r, 2}(\tau)
$$

The solution of (31) for a stable isotope is

$$
N_{s, 2}(\tau)=\frac{F(1-\beta)+D_{s}(1-F)}{(1-\beta F)\left[i+D_{s}(1-F)\right]} C_{s, 1}(0) M_{2}(\tau)
$$

and corresponding changes for radioactive and daughter isotopes have to be made in (13) and (15) given previously. The 
enrichment factor as defined in (17) is then given for reservoir 2 by

$$
f_{2}{ }^{r / s}=\left[\frac{F(1-\beta)+D_{r}(1-F)}{F(1-\beta)+D_{s}(1-F)}\right]\left[\frac{F+D_{s}(1-F)}{F+D_{r}(1-F)}\right]-1
$$

and this value should be used in (19) and (20). From the mass and species conservation equations given previously for this case written for radioactive and stable species it may be shown that

$D_{s}=\left\{\frac{(\beta-1) f_{2}^{r / s}+\beta\left[1-\left(C_{r, 3} / C_{r, 1}\right) F\right]}{\left(C_{r, 3} / C_{r, 1}\right) F \beta+f_{2}{ }^{r / s}}\right\} \frac{F}{1-F}>0$

Since $0<F\left(C_{r, 3} / C_{r, 1}\right)<1$, it follows from (34) that for $f_{2}^{r / s}$ $<0$ and $0<D_{r}<D_{s}<1$ that

$$
\beta>\left(C_{r, 3} / C_{r, 1}\right) F \beta>-f_{2}^{r / s}
$$

and for $f_{2}^{r / s}>0$ and $0<D_{s}<D_{r}<1$ we have that

$$
\beta>\frac{f_{2}^{r / s}}{f_{2}^{r / s}+1}
$$

Thus given a value for $f_{2}^{r / s}$, this may put serious constraints on the value of $\beta$. If, for example, the continents always occupied $1 / 3$ of the surface area and if the continents only grew from rising material by this geometrical consideration, then $\beta$ would be $1 / 3$. Were it possible to show that $\beta$ is very different from this, then this would indicate that the geometrical considerations were not controlling the rate of continental growth and some sweeping or disaggregation process was required. We note that the case with $\beta<1$ has many similarities with models involving refluxing of material from the crust to the depleted mantle. If a fraction $1-\beta$ of new additions to the crust is always immediately subducted back to the depleted mantle, then the exact solution of this problem is also given by (29)-(36) above. Similarly, these equations also describe the case where a fraction $1-\beta$ of the melt is always trapped in the residual solid. The conceptual pictures in Figure 1 and the descriptions of model $I$ in the text do not fully describe the variety of physical circumstances which are represented by the equations derived for model I.

\section{Model II}

We now consider a model where the continental crust 3 grows from an initially undifferentiated mantle reservoir 2 which is depleted at all times subsequent to $\tau=0$ as a result of crustal growth. This reservoir 2 may make up all or part of the mantle. We define a reference reservoir 1 which corresponds to the total of reservoirs 2 and 3 . Initially, the whole mantle is supposed to be homogeneous and undifferentiated. A remaining portion of the mantle which is not involved in crust formation may remain isolated and undifferentiated. This reservoir will follow the isotopic evolution of the reference reservoir 1 but otherwise has nothing to do with the model. The model is shown in Figure 1. Let us assume that a differential mass is removed from reservoir 2 as a partial melt to form new crust and increases the mass of the crust by $\delta M_{3}$ and decreases the mass of reservoir 2 by $\delta M_{2}=-\delta M_{3}$. The concentration of an element $i$ in the partial melt at time $\tau$ is $c_{r, 3}(\tau)$.

There are two different cases of this model that merit discussion. For case $\mathrm{A}$, assume that the differential melt $\delta M_{3}$ equilibrates with all of reservoir 2 . Then the mass of the residue is all of reservoir 2 , and the degree of melting $F=\delta M_{3}$ / $M_{2}$ must be a differential. This means that for an element $i$ with bulk distribution coefficient $D_{i}=0$ all of the element would be transported into the crust as soon as any differential melt formed from reservoir 2 . This does not seem physically realistic. For case $B$, assume that a differential mass $\delta M^{*}$ of reservoir 2 is differentiated into a melt $\delta M_{3}$ and a residue $\delta M_{R}{ }^{*}$ with the degree of melting $F$ being finite. Case B seems physically more realistic than case $A$. For case $B$ we have that $\delta M_{3} / \delta M^{*}=F$ and $\delta M_{R}^{*} / \delta M^{*}=1-F$. The residue after removal of a melt fraction from reservoir 2 is assumed to be homogenized instantaneously with the remaining part of the depleted mantle. Conservation of species and mass gives $C_{i, 2}(\tau) \delta M^{*}=c_{i, 3}(\tau) \delta M_{3}+c_{i, R}(\tau) \delta M_{R}^{*}$, and since $c_{i, R}(\tau) / c_{i, 3}(\tau)$ $\equiv D_{l}$, it follows that $c_{1,3}(\tau)=d_{1} C_{1,2}(\tau)$, where

$$
d_{i} \equiv 1 /\left[F+D_{d}(1-F)\right]
$$

This case thus corresponds to the melting law in model $I$. The difference is that in model II the residue always has to be homogenized with the remaining part of the mantle reservoir it is derived from, and this reservoir is continuously depleted. Case B will be used in the following discussion.

The number of species $i$ in the differential melt $\left(\delta M_{3}\right)$ that is added to the crust is given by

$$
\delta N_{i, 3}(\tau)=c_{i, 3}(\tau) \delta M_{3}=d_{i} \frac{\delta M_{3}}{M_{2}(\tau)} N_{i, 2}(\tau)
$$

If $\delta \tau$ is the time over which the mass $\delta M_{3}$ is added to the continental crust, then the transport equations for reservoirs $j=$ 2,3 are

$$
\begin{array}{rr}
\frac{d N_{i,(}(\tau)}{d \tau}=(-1)^{j+1}\left(\frac{\delta N_{i, 3}}{\delta \tau}\right)-\lambda_{i} N_{r, d}(\tau) & \\
\lambda_{1}=0 & i=s \\
\lambda_{i}=\lambda_{r} & i=r \\
\lambda_{i}=-\lambda_{r} & i=d
\end{array}
$$

For simplicity we again ignore mass transport from 3 to 2 . Using the expression for $\delta N_{i, 3}$ and calling $\delta M_{3} / \delta \tau \equiv M_{3}^{\prime}(\tau)$, we obtain the following basic transport equations for model II:

$$
\frac{d N_{t,}(\tau)}{d \tau}=(-1)^{j+1} d_{1} \frac{M_{3}^{\prime}(\tau)}{M_{2}(\tau)} N_{\iota, 2}(\tau)-\lambda_{t} N_{r,}(\tau)
$$

The masses of the total reservoirs 2 and 3 must satisfy

$$
M_{2}(\tau)+M_{3}(\tau)=M_{2}(0) \quad M_{2}^{\prime}(\tau)=-M_{3}^{\prime}(\tau)
$$

The integrals of the transport equations for a stable species $s$ in reservoirs 2 and 3 are

$$
\begin{gathered}
N_{s, 2}(\tau)=N_{s, 2}(0)\left[\frac{M_{2}(\tau)}{M_{2}(0)}\right]^{d s} \\
N_{s, 3}(\tau)=N_{s, 2}(0)-N_{s, 2}(\tau)
\end{gathered}
$$

Equation (42) for a stable isotope in reservoir 2 may be written in the following form:

$$
C_{s, 2}(\tau)=C_{s, 2}(0)\left[1-\frac{M_{3}(\tau)}{M_{2}(0)}\right]^{\left(d_{s}-1\right)}
$$

This expression has the same general form as the equation of Shaw [1970] for the solid residue after modal fractional (Rayleigh) melting, however, $d_{s}$ takes the place of the inverse bulk distribution coefficient and the degree of crust formation $M_{3}(\tau) / M_{2}(0)$ takes the place of the degree of melting. 
The solutions of (40) for radioactive and daughter isotopes are

$$
\begin{gathered}
N_{r, 2}(\tau)=N_{r, 2}(0) e^{-\lambda \tau}\left[\frac{M_{2}(\tau)}{M_{2}(0)}\right]^{d_{r}} \\
N_{r, 3}(\tau)=N_{r, 2}(0) e^{-\lambda \tau}-N_{r, 2}(\tau) \\
N_{d, 2}(\tau)=\left\{N_{d, 2}(0)+N_{r, 2}(0) \lambda \int_{0}^{\tau}\left[\frac{M_{2}(\xi)}{M_{2}(0)}\right]^{\left(d_{r}-d_{s}\right)}\right. \\
\cdot \exp [-\lambda \xi] d \xi\}\left[\frac{M_{2}(\tau)}{M_{2}(0)}\right]^{d_{s}} \\
N_{d, 3}(\tau)=N_{d, 2}(0)+N_{r, 2}(0)\left[1-e^{-\lambda \tau}\right]-N_{d, 2}(\tau)
\end{gathered}
$$

where $d_{s}=d_{d}$, since $d$ and $s$ are isotopes of the same element. The ratios of a radiogenic isotope to a stable isotope for the two reservoirs are

$\frac{N_{d, 2}(\tau)}{N_{s, 2}(\tau)}=\frac{N_{d, 1}(\tau)}{N_{s, 1}(\tau)}-\lambda \frac{N_{r, 1}(\tau)}{N_{s, 1}(\tau)} \int_{0}^{\tau}\left\{1-\left[\frac{M_{2}(\xi)}{M_{2}(0)}\right]^{\left(d_{r}-d_{s}\right)}\right\}$

$$
\cdot \exp [\lambda(\tau-\xi)] d \xi
$$

$\frac{N_{d, 3}(\tau)}{N_{s, 3}(\tau)}=\frac{N_{d, 1}(\tau)}{N_{s, 1}(\tau)}-\lambda \frac{N_{r, 1}(\tau)}{N_{s, 1}(\tau)}$

$\left\{\int_{0}^{\tau}\left[1-\left(\frac{M_{2}(\xi)}{M_{2}(0)}\right)^{\left(d_{r}-d_{s}\right)}\right] \exp [\lambda(\tau-\xi)] d \xi\right)\left[1-\left(\frac{M_{2}(\xi)}{M_{2}(0)}\left(-d_{s}\right)\right]^{-1}\right.$

From (17) and (42)-(45) the enrichment factors of the ratio of a radioactive isotope to a stable isotope in the total reservoirs 2 and 3 to that in reservoir 1 are given by

$f_{2}{ }^{r / s}(\tau)=\left[\frac{M_{2}(\tau)}{M_{2}(0)}\right]^{\left(d_{r}-d_{s}\right)}-1 \approx \exp \left[-\left(d_{r}-d_{s}\right) \frac{M_{3}(\tau)}{M_{2}(0)}\right]-1$

$\frac{f_{2}^{r / s}(\tau)}{f_{3}^{r / s}(\tau)}=1-\left[\frac{M_{2}(\tau)}{M_{2}(0)}\right]^{\left(-d_{s}\right)} \approx 1-\exp \left[d_{s} \frac{M_{3}(\tau)}{M_{2}(0)}\right]$

where the approximations hold for the mass of the crust much smaller than that of the depleted mantle $\left[\left(M_{3}(\tau) / M_{2}(0)\right) \ll 1\right]$. Equations (48) and (49) may be written in terms of deviations in parts in $10^{4}$ from the reference reservoir 1 :

$$
\begin{gathered}
\epsilon_{d, 2}{ }^{*}(\tau)=Q_{d}{ }^{*}(\tau) \int_{0}^{\tau} f_{2}{ }^{r / s}(\xi) \exp [\lambda(\tau-\xi)] d \xi \\
\epsilon_{d, 3}{ }^{*}(\tau)=\epsilon_{d, 2}{ }^{*}(\tau) \frac{f_{3}^{r / s}(\tau)}{f_{2}^{r / s}(\tau)}
\end{gathered}
$$

where $Q_{d}{ }^{*}(\tau)$ is defined by (20). Equations (50)-(53) in conjunction with (37) are the basic equations for calculations with this model for arbitrary rates of crustal growth. In this class of models the average enrichment factors are a function of the time and correspond to a time dependent chemical evolution. For $\lambda \tau \ll 1$ the deviation $\epsilon_{d_{y}}{ }^{*}$ are then proportional to the weighted time average of the enrichment factors $\left\langle f_{j}^{r / s}\right\rangle$ and given by

$$
\begin{gathered}
\epsilon_{d, 2}{ }^{*}(\tau)=Q_{d}{ }^{*}(\tau)\left(f_{2}{ }^{r / s}(\tau)\right) \tau \\
\epsilon_{d, 3}{ }^{*}(\tau)=Q_{d}{ }^{*}(\tau) \frac{f_{3}^{r / s}(\tau)}{f_{2}^{r / s}(\tau)}\left(f_{2}^{r / s}(\tau)\right\rangle \tau
\end{gathered}
$$

This means that the simple species independent time averages which govern the $\epsilon$ function for models of type I no longer apply, and an average age is not directly applicable to reservoir 2.

In this model the depleted mantle is assumed to always be homogeneous. For the crust the equations give the average values. If each new addition to the crust is isolated, then the new individual segments follow their own evolutionary path. The initial states of new additions to 3 at time $\tau^{\prime}$ are given by

$$
\begin{gathered}
f_{\text {new }}{ }^{\prime s}\left(\tau^{\prime}\right)=\frac{d_{r}}{d_{s}}\left[f_{2}^{r / s}\left(\tau^{\prime}\right)+1\right]-1 \\
\epsilon_{d, \text { new }}{ }^{*}\left(\tau^{\prime}\right)=\epsilon_{d, 2}{ }^{*}\left(\tau^{\prime}\right)
\end{gathered}
$$

and subsequent evolution will follow:

$\epsilon_{d, \text { new }}{ }^{*}(\tau)=\epsilon_{d, 3}{ }^{*}\left(\tau^{\prime}\right)+\frac{Q_{d}^{*}(\tau)}{\lambda} f_{\text {gew }}{ }^{r / s}\left(\tau^{\prime}\right)\left\{\exp \left[\lambda\left(\tau-\tau^{\prime}\right)\right]-1\right\}$

This model has the property that new crust would at the time of addition have the isotopic values of depleted mantle 2, and the interpretation of $T_{\mathrm{CHUR}}{ }^{\mathrm{Nd}}$ model ages [McCulloch and Wasserburg, 1978] of new crust would depend on the detailed history of reservoir 2.

For this model we may again define the mean age of species $s$ in the crust 3 by

$\bar{t}_{s, 3}=\frac{1}{N_{s, 3}(\tau)} \int_{0}^{\tau}(\tau-\xi) \frac{d N_{s, 3}}{d \xi} d \xi=\frac{1}{N_{s, 3}(\tau)} \int_{0}^{\tau} N_{s, 3}(\xi) d \xi$

and the mean age of the mass $M_{3}$ by

$\bar{t}_{M, 3}=\frac{1}{M_{3}(\tau)} \int_{0}^{\tau}(\tau-\xi) M_{3}^{\prime}(\xi) d \xi=\frac{1}{M_{3}(\tau)} \int_{0}^{\tau} M_{3}(\xi) d \xi$

The mean age of the depleted mantle reservoir 2 may not be defined in the same manner. Note that for model II, $N_{s, 3}(\tau) /$ $M_{3}(\tau)$ is not a constant independent of $\tau$, so that $\bar{t}_{s, 3} \neq \bar{t}_{M, 3}$. The result of this is distinct from model $I$ and is shown schematically in Figure 2. Using (43) and (59), we may write

$$
\begin{aligned}
\bar{t}_{s, 3} & =\left\{1 /\left[1-\left(1-\frac{M_{3}(\tau)}{M_{2}(0)}\right)^{d s}\right]\right\} \int_{0}^{\tau}\left[1-\left[1-\frac{M_{3}(\xi)}{M_{2}(0)}\right]^{d_{s}}\right\} d \xi \\
& \approx\left\{1 /\left[1-\exp \left(-\frac{d_{s} M_{3}(\tau)}{M_{2}(0)}\right)\right]\right\} \int_{0}^{\tau}\left\{1-\exp \left[-d_{s} \frac{M_{3}(\xi)}{M_{2}(0)}\right]\right\} d \xi
\end{aligned}
$$

assuming that $\left(M_{3}(\tau) / M_{2}(0)\right) \ll 1$ in the second expression. In the case that $\left[d_{s} M_{3}(\tau) / M_{2}(0)\right] \ll 1$, then $\bar{t}_{s, 3} \approx \bar{t}_{M, 3}$. If $\left[d_{s} M_{3}(\tau) /\right.$ $\left.M_{2}(0)\right] \gg 1$ for $\tau \geq \tau^{*}$, then $\bar{t}_{s, 3} \approx$ const $+\left(\tau-\tau^{*}\right)$ for $\tau \geq \tau^{*}$, and $\left(d \bar{t}_{s, 3} / d \tau\right)=1$. This corresponds to the bulk of the species $s$ being transported into the crust by time $\tau^{*}$ after the formation of the earth. The mass transfer is then subsequently decoupled from addition of the trace element $s$, and the average age of the mass $\bar{t}_{M, 3}$ may be substantially younger than $\bar{t}_{s, 3}$ as the different trace element abundances of the crust change with time. The difference between $\bar{t}_{s, 3}$ and $\bar{t}_{M, 3}$ is of interest and may be evaluated quantitatively. We have

$$
\begin{aligned}
& \bar{t}_{s, 3}-\bar{t}_{M, 3}=\left\{\int _ { 0 } ^ { \tau } \left[M_{3}(\tau)-M_{3}(\xi)+M_{3}(\xi) \exp \left(-d_{s} \frac{M_{3}(\tau)}{M_{2}(0)}\right)\right.\right. \\
& \left.\left.-M_{3}(\tau) \exp \left(-d_{s} \frac{M_{3}(\xi)}{M_{2}(0)}\right)\right] d \xi\right\}\left\{\left[1-\exp \left(-d_{s} \frac{M_{3}(\tau)}{M_{2}(0)}\right)\right] M_{3}(\tau)\right\}^{-1}
\end{aligned}
$$




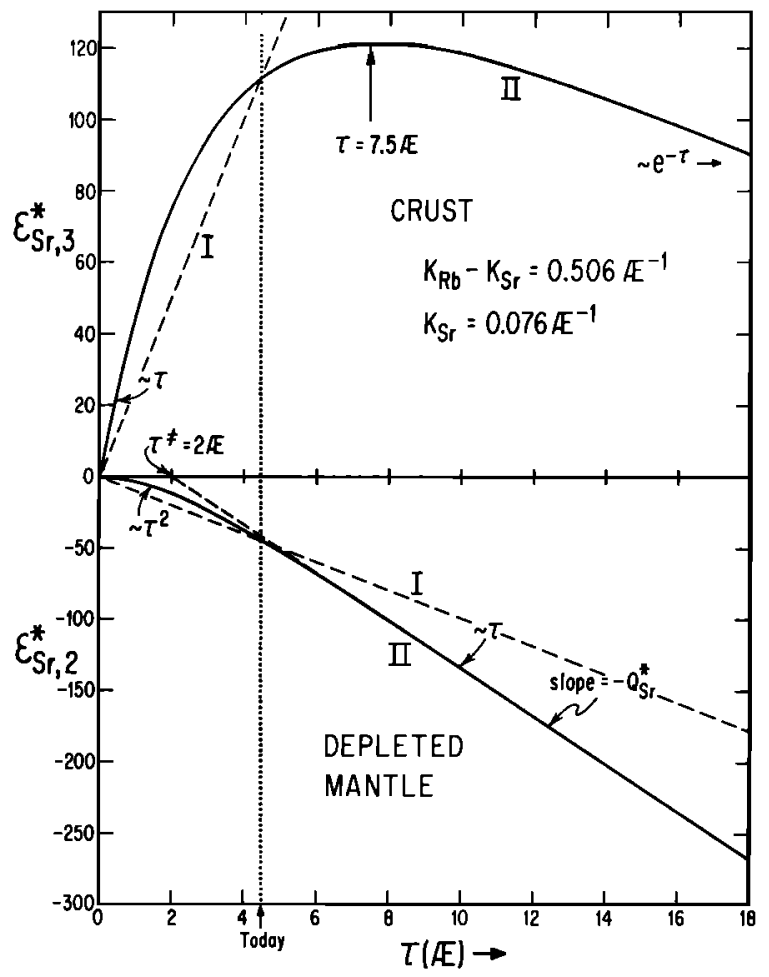

Fig. 3. Shown are $\epsilon_{\mathrm{S}_{\mathrm{r}}}{ }^{*}$ curves for the bulk depleted mantle (2) and the bulk crust (3) as a function of time $\tau$ for a constant rate of growth of the crust. Curves that give the same present day $\varepsilon_{\mathrm{Sr}^{*}}$ values are shown for both model I and model II and are identified by the symbols I and II, respectively. Note the marked difference in behavior for $\boldsymbol{\varepsilon}_{\mathbf{S}_{\mathbf{r}}}{ }^{*}$ as a function of time $\tau$ for the two models. Model $I$ is a straight line for both reservoirs, and model II starts out as nearly a straight line for the crust but with a significantly different slope. The curves for model II are constrained to give $f_{2}^{\mathrm{Rb} / \mathrm{Sr}}=-0.9$ and $f_{3}{ }^{\mathrm{Rb} / \mathrm{Sr}_{\mathrm{r}}}=$ +2.18 today. The implied values of $K_{\mathrm{Rb}}-K_{\mathrm{S}_{\mathrm{r}}}$ and $K_{\mathrm{S}_{\mathrm{r}}}$ are given. The systematics shown is valid for decay systems with $\lambda \tau \ll 1$ and $\left(d_{r}-d_{s}\right)$ $>0$.

$$
\begin{aligned}
& =\left\{( \frac { d _ { s } } { M _ { 2 } ( 0 ) } ) ^ { 2 } \int _ { 0 } ^ { \tau } M _ { 3 } ( \xi ) \left[\sum _ { n = 2 } ^ { \infty } \frac { ( - 1 ) ^ { n } } { n ! } \left(M_{3}(\tau)\left(\frac{d_{s} M_{3}(\tau)}{M_{2}(0)}\right)^{n-2}\right.\right.\right. \\
& \left.\left.\left.\left.-M_{3}(\xi)\left(\frac{d_{s} M_{3}(\xi)}{M_{2}(0)}\right)^{n-2}\right]\right] d \xi\right\}\left\{1-\exp \left(-d_{s} \frac{M_{3}(\tau)}{M_{2}(0)}\right)\right]\right\}^{-1}
\end{aligned}
$$

If $d_{s}<0$, it may be seen that $\bar{t}_{s, 3}-\bar{t}_{M, 3}<0$. This expression converges rather well even for large values of $d_{s}\left[M_{3}(\tau) / M_{2}(0)\right]$ $(\leqslant 2)$. In the limit for small $d_{s} / M_{2}(0)$ we have rather precisely

$$
\frac{\bar{t}_{s, 3}-\bar{t}_{M, 3}}{\left(d_{s} / M_{2}(0)\right)} \approx \frac{1}{2 M_{3}(\tau)} \int_{0}^{\tau} M_{3}(\xi)\left[M_{3}(\tau)-M_{3}(\xi)\right] d \xi
$$

so in this approximation, $\bar{t}_{s, 3}-\bar{t}_{M, 3}>0$ for $d_{s}>0$. For a model of a constant rate of crustal growth we obtain

$$
\bar{t}_{s, 3}-\bar{t}_{M, 3} \approx \frac{d_{s} M_{3}(\tau)}{12 M_{2}(0)} \tau
$$

which gives a difference of 0.65 eon for $d_{s}=100$ with $M_{3}(\tau)$ / $M_{2}(0)=0.0174$. It follows that for $d_{s} \leqslant 10$ there are only small differences in the mean ages.

We note that the expressions for $\epsilon^{*}((52)$ and (53)) may be written-in a form analogous to that for model $I$. Inspection of (61) and (52) shows that $\epsilon_{d .2}{ }^{*}$ may be written as

$$
\epsilon_{d, 2}{ }^{*}(\tau)=Q_{d}^{*}(\tau) f_{2}{ }^{r / s}(\tau) \bar{t}_{r / s}
$$

where

$$
\bar{t}_{r / s} \equiv \frac{1}{f_{2}^{r / s}(\tau)} \int_{0}^{\tau} f_{2}^{r / s}(\xi) d \xi=\frac{\tau\left(f_{2}^{r / s}(\tau)\right\rangle}{f_{2}^{r / s}(\tau)}
$$

The factor $\bar{t}_{r / s}$ is the time weighted average of $f_{2}^{r / s}$ for reservoir 2. If $d_{r}-d_{s}>0$, this is equivalent to the mean age of an element $r / s$ with a distribution coefficient $d_{r / s}=d_{r}-d_{s}$ and an enrichment factor $f_{2}^{r / s}$. Note that $\bar{t}_{r / s}$ is explicitly dependent on the particular parent-daughter system as distinct from. the case for model I. If the differentiation took place in only a single event, then $t_{r / s}=t_{M, 3}$. More generally, there will be a difference between $\bar{t}_{r / s}$ and $\bar{t}_{M, 3}$, which may be calculated from

$\bar{t}_{r / s}-\bar{t}_{M, 3} \approx \frac{d_{r}-d_{s}}{2 M_{3}(\tau) M_{2}(0)} \int_{0}^{\tau} M_{3}(\xi)\left[M_{3}(\tau)-M_{3}(\xi)\right] d \xi$

The derivation of expression (65) follows that given previously for $\bar{t}_{s, 3}-\bar{t}_{M, 3}$. For a model of constant rate of crustal growth we have

$$
\bar{t}_{r / s}-\bar{t}_{M, 3}=\frac{\left(d_{r}-d_{s}\right) M_{3}(\tau)}{12 M_{2}(0)} \tau
$$

If $\left|\left(d_{r}{ }^{r}-d_{s}\right) M_{3}(\tau) / M_{2}(0)\right| \ll 1$, then (50) and (52) may for very long lived isotopes be approximated by

$$
\epsilon_{d, 2}^{*}(\tau) \approx-\left(d,-d_{s}\right) \frac{Q_{d}^{*}(\tau) M_{3}(\tau)}{M_{2}(0)} \bar{t}_{M, 3}
$$

and

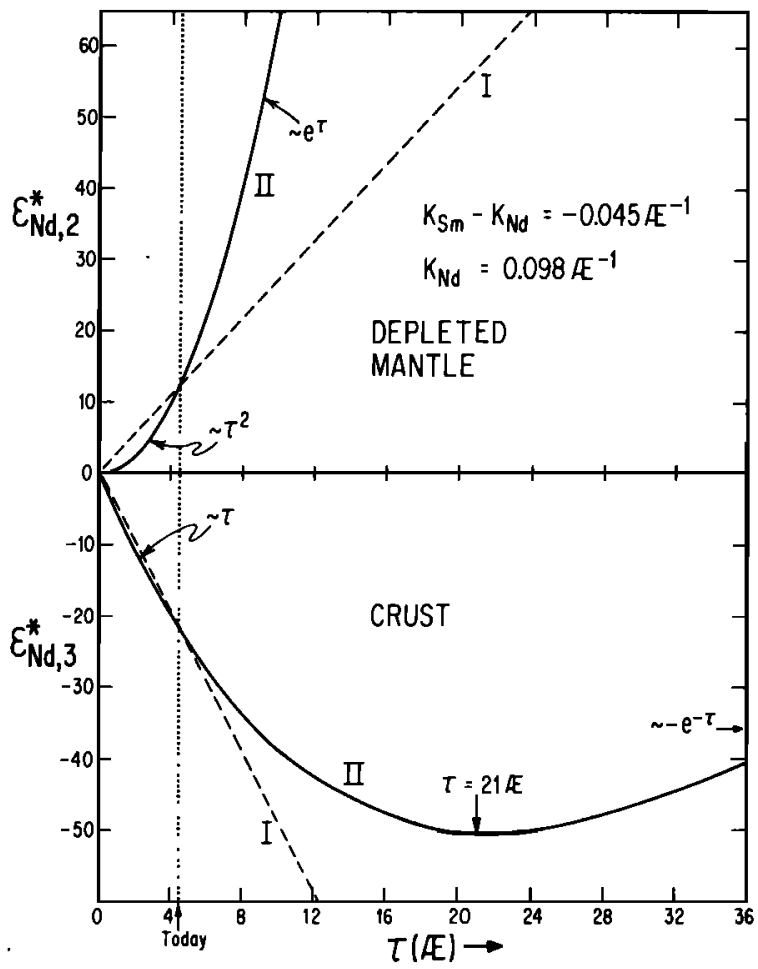

Fig. 4. Shown are $\epsilon_{\mathrm{Nd}_{y}}{ }^{*}$ curves for bulk depleted mantle (2) and bulk crust (3) as a function of time $\tau$ for a constant rate of growth of the crust. The notation is the same as in Figure 3. The curves for model II are constrained to give $f_{2}^{\mathrm{Sm} / \mathrm{Nd}}=+0.225$ and $f_{3}{ }^{\mathrm{Sm} / \mathrm{Nd}}=$ -0.4 today. The implied values of $K_{\mathrm{Sm}}-K_{\mathrm{Nd}}$ and $K_{\mathrm{Nd}}$ are shown. Note that the curves are reversed from those in Figure 3 owing to the change in sign of $K_{r}-K_{s}$. The systematics shown is valid for decay systems with $\lambda_{\tau} \ll I$ and $\left(d_{r}-d_{s}\right)<0$. 


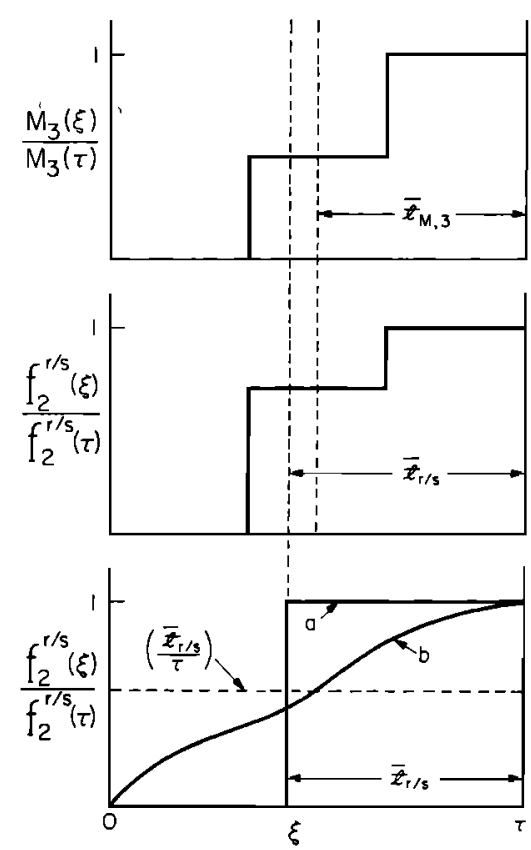

Fig. 5. Cartoon showing the relationship between the mean age of the mass of the crust $I_{M, 3}$, the mass growth curve of the crust $M_{3}$, the enrichment factor of the depleted mantle $f_{2}^{r / s}$, and the factor $t_{r / s}$ The upper diagram shows a mass growth curve where the crust is formed in two stages with a mean age $\bar{t}_{M, 3}$ at time $\tau$. The middle diagram shows the corresponding change in $f_{2}^{r / s}$ with time if $\left(d_{r}-d_{s}\right)=100$ and $\left[M_{3}(\tau) / M_{2}(\mathrm{O})\right]=0.0174$. The difference between $t_{r / s}$ and $t_{M, 3}$ is also indicated. If we know $i_{r / s} f_{2}^{r / s}$, and $M_{3}$ today, there is insufficient information to determine a unique solution for $M_{3}(\xi)$ and $f_{2}{ }^{\prime / s}(\xi)$. In the lower part of the diagram some other possible $f_{2}^{r / s}$ curves that give the same value for $t_{r / s}$ are shown. For a given curve, $f_{2}{ }^{r / s}$ with knowledge of $\left(d_{r}-d_{s}\right)$ determines a corresponding $M_{3}$ curve from (50). The area underneath the $\left[f_{2}^{r / s}(\xi) / f_{2}^{r / s}(\tau)\right]$ curve must be the same for all $M_{3}$ curves with the same value for $t_{r / s} ; t_{r / s}$ is the shortest time in which differentiation could have occurred as a single-stage process, and curve $a$ shows such an evolution. Curve $b$ shows a possible continuous curve. The dashed horizontal curve gives $\left[\left(V_{2}^{r / s}\right\rangle / f_{2}^{r / s}\right]=\left[t_{r / s} / \tau\right]$. All of these curves in the lower figure are compatible with the $t_{r / \mathrm{s}}$ fixed by the assumed model with $M_{3}(\xi)$ as given in the top and the $f_{2}^{r / s}(\tau)$ value.

$$
f_{2}^{r / s}(\tau) \approx-\left(d_{r}-d_{s}\right) \frac{M_{3}(\tau)}{M_{2}(0)}
$$

If it also holds that $\left[d_{s} M_{3}(\tau) / M_{2}(0)\right] \ll 1$, then

$$
f_{3}^{r / s}(\tau) \approx\left(d_{r} / d_{s}\right)-1
$$

and

$$
\epsilon_{d, 3}^{*}(\tau) \approx Q_{d}^{*}(\tau)\left[\left(d_{r} / d_{s}\right)-1\right] \bar{t}_{M, 3}
$$

An important special case is when $\left(d M_{3} / d \tau\right)$ is a constant. In this case, $M_{3}(\tau)=\left\lceil M_{3}\left(T_{0}\right) / T_{0}\right] \tau$, and defining $K_{i} \equiv$ $\left[\left(d_{i} M_{3}\left(T_{0}\right)\right) /\left(T_{0} M_{2}(0)\right)\right]$ then for very long lived isotopes,

$$
\begin{gathered}
\epsilon_{d, 2}{ }^{*}(\tau)=-Q_{d}^{*}(\tau)\left\{\tau-\frac{1-\exp \left[-\left(K_{r}-K_{s}\right) \tau\right]}{\left(K_{r}-K_{s}\right)}\right\} \\
f_{2}^{r / s}(\tau)=\exp \left[-\left(K_{r}-K_{s}\right) \tau\right]-1 \\
\frac{f_{2}^{r / s}(\tau)}{f_{3}{ }^{r / s}(\tau)}=1-\exp \left(K_{s} \tau\right) \\
\epsilon_{d, 3}{ }^{*}(\tau)=\frac{\epsilon_{d, 2}^{*}(\tau)}{1-\exp \left(K_{s} \tau\right)}
\end{gathered}
$$

There are two different classes of solutions depending on whether $\left(d_{r}-d_{s}\right)$ is negative (as for Sm-Nd) or positive (as for
$\mathbf{R b}-\mathrm{Sr}$ ). Examples are shown for Rb-Sr and Sm-Nd in Figures 3 and 4, respectively. For short times we have in both cases that $\epsilon_{d, 2}{ }^{*} \propto \tau^{2}$ and $\epsilon_{d, 3}{ }^{*} \propto \tau$. For long times we get $\epsilon_{\mathrm{Sr}, 2}{ }^{*} \approx$ $-Q_{\mathrm{Sr}}{ }^{*}\left(\tau-\tau^{\dagger}\right)$, where $\tau^{\dagger}=1 /\left(K_{\mathrm{Rb}}-K_{\mathrm{Sr}}\right)=2$ aeons and $\epsilon_{\mathrm{Nd}, 2}{ }^{*} \propto$ $\exp \left[-\left(K_{\mathrm{Sm}}-K_{\mathrm{Nd}}\right) \tau\right]$ for the depleted mantle. The curves for the crust go to an extremum and then asymptotically approach zero. The inclusion of the term $\exp [\lambda(\tau-\xi)]$ for shorter-lived isotopes in the exact integral of (52) will, of course, quantitatively alter the nature of these results. The curve for $\epsilon_{\mathrm{S}_{\mathrm{r}, 3}}{ }^{*}$ has a maximum at $\tau=7.5$ aeons, and for much longer times $\epsilon_{\mathrm{Sr}, 3} \propto \exp \left[-K_{\mathrm{Sr}} \tau\right]$. Similarly, the $\epsilon_{\mathrm{Nd}, 3} *$ curve for the crust has a minimum at $\tau=21$ aeons, and $\epsilon_{\mathrm{Nd}, 3} \propto-\exp$ $\left[-K_{\mathrm{Nd}} \tau\right]$ for much longer times. These solutions enable us to qualitatively understand the nature of the results for more general jases of crustal growth with time. From these results we may infer that for any continuous or multiepisodic mass growth of the crust the basic isotopic systematics for longlived isotopes must follow those outlined in Figures 3 and 4. We note that for the case of episodic mass growth, $\epsilon_{d, 3}$ " will be discontinuous owing to the factor $f_{3}^{r / s} / f_{2}^{r / s}$ outside of the integral in (53). The value of $\epsilon_{d, 2}{ }^{*}$ for the depleted mantle will still be continuous but will show changes in slope corresponding to the discontinuities in the mass growth curve. The general case for arbitrary mass transport is of course included in the exact basic equations (50)-(53).

Calculations with model II are more complex than with model $\mathrm{I}$, where the average age $\bar{t}$ is independent of species. For the mantle we have previously obtained the exact results:

$$
\epsilon_{d, 2}{ }^{*}=Q_{d}{ }^{*}(\tau)\left\langle f_{2}^{r / s}\right) \tau=Q_{d}{ }^{*}(\tau) f_{2}^{r / s}(\tau) t_{r / s}
$$

It follows that if $\epsilon_{d, 2}{ }^{*}(\tau)$ is known at $\tau$, then $\left\langle f_{2}{ }^{r / s}\right\rangle$ is determined. If $\epsilon_{d, 2}{ }^{*}$ and $f_{2}^{r / s}$ are known, then $\left(d_{r}-d_{s}\right)$ is known from (50), and $\bar{t}_{r / s}$ is determined; $\bar{t}_{r / s}$ is the time required to generate $\epsilon_{d, 2}{ }^{*}$ with the present value of $f_{2}^{r / s}$. As $f_{2}^{r / s}$ is monotonic in this model, $\bar{t}_{r / s}$ is the shortest time in which differentiation could have occurred (as a single-stage process). All possible crustal mass growth laws $M_{3}(\tau)$ must satisfy the relationship between $f_{2}^{r / s}$ and $M_{3}$. The relationships are shown schematically in Figure 5. If decay schemes with very long lived parents have $\left|\left(d_{r}-d_{s}\right) M_{3} / M_{2}(0)\right| \ll 1$, then they will all yield the same values of $\bar{t}_{r / s}$ and no further information may be derived about the change of $M_{3}$ with time from the different systems at one time $\tau$. If two systems have distinctive parameters (such as $\mathbf{R b}-\mathrm{Sr}$ and $\mathrm{Sm}-\mathrm{Nd}$ ), then they will have different values of $\bar{t}_{r / s}$ which will give more information about $M_{3}(\tau)$. For $N$ independent values of $\bar{t}_{r / s}$ from $N$ different decay schemes with $\lambda \tau \ll 1$, it is, in principle, possible to calculate models of multiple-stage mass evolution with time. For example, for an $n$ stage evolution we write

$$
\bar{t}_{r / s}=\sum_{i=1}^{n} \frac{\exp \left[-\alpha_{r / s} X_{i-1}\right]-1}{\exp \left[-\alpha_{r / s}\right]-1}\left(\tau_{i}-\tau_{i-1}\right)
$$

where $\tau_{0}=0, \tau_{n}=\tau, X_{n-1}=1$, and $X_{0}=0$. The solutions for $X_{i}$ may in general not be a unique description of earth evolution. Here $X_{1}-X_{1-1}$ is the fraction of $M_{3}(\tau)$ made at time $\tau_{i}$, and $\alpha_{r / s}=\left(d_{r}-d_{s}\right) M_{3}(\tau) / M_{2}(0)$. Such equations may be solved numerically for the $X_{i}$ and $\tau_{i}$ which must provide simultaneous solutions for different $\bar{t}_{r / s}$ values. In the degenerate case when $\alpha_{r / s} \ll 1$,

$$
\bar{t}_{r / s}=\sum_{i=1}^{n} X_{i-1}\left(\tau_{i}-\tau_{t-1}\right)
$$

which is independent of $r / s$. 
TABLE 2. Masses of Various Reservoirs in the Earth

\begin{tabular}{lcl}
\hline \multicolumn{1}{c}{ Reservoir } & $\begin{array}{c}\text { Mass, } \\
10^{25} \text { grams }\end{array}$ & $\begin{array}{c}\text { Fraction } \\
\text { of Total } \\
\text { Earth Mass }\end{array}$ \\
\hline $\begin{array}{l}\text { Continental crust } \\
\text { Subcontinental crust }\end{array}$ & 1.807 & 0.003023 \\
Oceanic sediment (layer 1)* & 0.430 & 0.000719 \\
Total continental crust plus sub- & 0.019 & 0.000032 \\
$\quad$ continental crust plus oceanic & & \\
$\quad$ sediment & 2.256 & 0.003774 \\
Oceanic crust (layers 2 and 3) $\dagger$ & 0.590 & 0.000987 \\
Mantle & 400.5 & 0.6701 \\
Mantle plus crust & 403.4 & 0.6749 \\
Core & 194.3 & 0.3251 \\
Total earth & 597.7 & 1 \\
\hline
\end{tabular}

Masses of core and mantle are from Smith [1971], and masses of the crustal reservoirs are from Renov and Yaroshevsky [1976].

*Considered to be mainly derived by werathering of continental crust.

†Basaltic part of the oceanic crust.

\section{BOUNDARY CONDITIONS FOR THE MODELS}

The parameters involved for both models described above are the initial and final concentrations and isotopic compositions for each reservoir $j$, the solid/melt distribution coefficients, and the mass of reservoir $j$ as a function of time. All these parameters need not be specified, and in the following we will choose the parameters we believe are the best known and use them to make estimates of others. We will limit the discussion to the Rb-Sr and Sm-Nd decay systems, but their relation to the concentrations of $\mathrm{K}, \mathrm{Ba}$, and $\mathrm{U}$ will also be discussed. The masses of the various reservoirs in the earth are given in Table 2. In both models the depleted mantle is taken to include the basaltic part of the oceanic crust, since it is derived from the depleted mantle and is subducted back to the depleted mantle at a short time scale $(<0.2$ aeon). The total mass of the continental crust $\left(2.256 \times 10^{25}\right.$ grams) is taken as the total amount of continental materials including layer 1 of the oceanic crust, which is considered to be mainly sediments derived from weathering of continental crust. The bulk earth values (reservoir 1 ) used for $\mathbf{R b}-\mathrm{Sr}$ and $\mathrm{Sm}-\mathrm{Nd}$ are given in the appendix. By definition, $\epsilon_{d, 1}=f_{1}^{r / s}=0$ for reservoir 1 (undepleted mantle). Estimates of $\epsilon$ and $f$ values for the depleted mantle and the continental crust are given in Table 3 , and partition coefficients for garnet peridotite minerals in Table 4. The values for the depleted mantle in Table 3 are the estimates for the MORB source given by Jacobsen and Wasserburg [1979], where the estimates for 0.5 aeon ago are based on data from the Bay of Islands complex.

The silicate portion of the earth is assumed to be initially chemically homogeneous, and the core is assumed to have insignificant amounts of the lithophile elements considered here. The concentrations of these elements in the silicate portion of the earth are thus 1.48 times their concentrations in the total earth. It is known that the earth is depleted in volatile elements relative to chondrites [Gast, 1960]. However, the ratios of refractory elements in the earth appear to be equal to those in chondrites from both isotopic studies [DePaolo and Wasserburg, 1976a] and chemical studies [Sun and Nesbitt, 1977]. This gives a minimum of 1.48 times chondritic abundances for these elements in the silicate portion of the earth. If a steady state relationship between heat production from radioactive sources and heat flow exist, then the $U$ content of the crust plus mantle is $35 \mathrm{ppb}$ [Wasserburg et al., 1964; Tera et al., 1974] or $46 \mathrm{ppb}$ if the new global heat flow estimate of Williams and Von Herzen [1975] is used [O'Nions and Pankhurst, 1977]. Ordinary chondrites have $13 \mathrm{ppb} U$, so the heat flow data give an upper limit of 2.7 or 3.5 times chondrites for the concentration of $U$ and other refractory elements for the silicate portion of the earth. It has been concluded elsewhere that the concentrations of $\mathrm{Ca}, \mathrm{Al}, \mathrm{U}, \mathrm{Th}, \mathrm{Ba}, \mathrm{Sr}$, and $\mathrm{REE}$ in the mantle are about $2.0 \pm 0.5$ those in ordinary chondrites [Frey and Green, 1974; Loubet et al., 1975; Sun and Nesbitt, 1977]. We have thus used a value 2 times ordinary chondrites for the refractory elements in the crust plus mantle. Estimates for the $\mathbf{R b}$ and $\mathrm{K}$ concentrations in the silicate portion of the earth can then be estimated from the bulk earth $\mathrm{Rb} / \mathrm{Sr}$ ratio of 0.029 [DePaolo and Wasserburg, 1976 b] and the bulk earth $K / U$ ratio. Previous estimates of the $K / U$ ratio of the earth [Heier and Rogers, 1963; Wasserburg et al., 1964] were based mainly on upper crustal rocks and are very close to $10^{4}$. This is most likely a lower limit, since lower crustal granulites have $(\mathrm{K} / \mathrm{U})>10^{4}$ [Lambert and Heier, 1968b] and since it seems plausible that $U$ is more enriched in the crust than $K$. Our estimates of the concentrations of $\mathrm{K}, \mathrm{U}, \mathrm{Ba}, \mathrm{Rb}, \mathrm{Sr}, \mathrm{Sm}$, and $\mathrm{Nd}$ in the crust plus mantle are compared with other recent estimates in Table 5. Most estimates agree to within a factor of 2. The largest disagreement for element ratios is with the $\mathrm{Sm} / \mathrm{Nd}$ ratio of Smith [1977] and the Sr/Nd ratio of O'Nions et al. [1978].

Extensive work has established that the upper crustal composition is close to that of granodiorite [Poldervaart, 1955; Shaw et al., 1967; Eade and Fahrig, 1971]. The most recent estimates for the elements of interest here [Shaw et al., 1976] are given in Table 6. It is well known from the heatflow data that the upper crustal concentrations of $K, U$, and $T h$ cannot extend to a depth of more than $10-15 \mathrm{~km}$, so that the lower crust must be depleted in these elements [Heier, 1965, 1973]. This had led to the hypothesis that the lower crust is made up of dry granulite facies rocks and related igneous rocks, since they show the necessary depletions in $\mathrm{U}$ and Th [Heier, 1965], and they also show $\mathrm{Rb}$ depletions and generally low $\mathrm{Rb} / \mathrm{Sr}$ ratios [Heier, 1964]. Extensive geochemical studies of granulite facies rocks with particular emphasis on the distribution of heat-producing elements have been carried out in Australia and Norway [Heier and Adams, 1965; Lambert and Heier, 1967, 1968a, b; Heier and Thoresen, 1971]. The estimates of

TABLE 3. Ranges of Parameters Based on Directly Observed Average Values

\begin{tabular}{lccccc}
\hline & $T$, aeons & $f^{\mathrm{Rb} / \mathrm{Sr}}$ & $\epsilon_{\mathrm{Sr}}$ & $f^{\mathrm{Sm} / \mathrm{Nd}}$ & $\epsilon_{\mathrm{Nd}}$ \\
\hline Depleted mantle & 0 & $-0.9+0.1$ & $-27 \pm 5$ & $+0.22+0.08$ & $+10 \pm 2$ \\
& 0.5 & -0.9 & -19.3 & -0.07 & +7.6 \\
Continental crust & 0 & +1 to +10 & +60 to +250 & $-0.4 \pm 0.1$ & -10 to -25 \\
\hline
\end{tabular}

Sources are McCulloch and Wasserburg [1978], DePaolo and Wasserburg [1979a], and Jacobsen and Wasserburg [1979]. 
TABLE 4. Mineral/Melt and Bulk Partition Coefficients

\begin{tabular}{llllllll}
\hline & K & Rb & Sr & Ba & Nd & Sm & U \\
\hline Clinopyroxene & 0.003 & 0.003 & 0.12 & 0.002 & 0.17 & 0.26 & 0.003 \\
Garnet & 0.006 & 0.01 & 0.08 & 0.003 & 0.087 & 0.217 & 0.003 \\
Orthopyroxene & 0.003 & 0.003 & 0.02 & 0.002 & 0.013 & 0.022 & 0.0001 \\
Olivine & 0.0002 & 0.0002 & 0.0002 & 0.0001 & 0.007 & 0.010 & 0.0001
\end{tabular}

Initial bulk

distribution

coefficient*

$D_{0, K}$

$D_{0, R b}$

$D_{0, \mathrm{Sr}}$

$D_{0, B a}$

$D_{0, \mathrm{Nd}}$

$D_{0, \mathbf{S m}}$

$D_{0, \mathrm{U}}$

0.002

0.0025

0.033

0.0014

0.044

0.080

Sources: Griffin and Murthy [1969], Philpotts and Schnetzler [1970], Schnetzler and Philpotts [1970], Hart and Brooks [1974], Shimizu [1974], Grutzeck et al. [1975], Shimizu and Kushiro [1975], Weill and McKay [1975], McKay and Weill [1976], Benjamin et al. [1978].

$D_{\mathrm{U}}{ }^{c p x / 0 l} \approx D_{\mathrm{U}}{ }^{c p x / o p x} \approx 30$, Tatsumoto [1978].

$D_{\mathrm{U}}^{c p x / g o} \approx 1$, Morgan and Lovering [1971].

"Calculated for a garnet peridotite mineralogy with the following initial mass fractions of the various phases: olivine $=0.55$, orthopyroxene $=$ 0.15 , clinopyroxene $=0.15$, garnet $=0.15$.

the concentrations in the lower crust from Heier and Thoresen [1971] are given in Table 6. Lambert and Heier [1968b] used estimates of the heat-producing elements in upper and lower crustal materials together with constraints from heatflow to calculate concentration profiles of $K, U$, and $T h$ through the continental crust. They estimated total crust concentrations of $K=1.5 \mathrm{wt} \%$ and $U=0.7 \mathrm{ppm}$ for Precambrian shields. Similar reasoning gives $K / R b \approx \mathbf{4 5 0}$ for the total crust on the basis of upper and lower crustal $K$ and $R b$ concentrations. To arrive at the estimates we give for the total crust in Table 6, we have used the estimates of Lambert and Heier [1968b] for $\mathrm{K}$ and $\mathrm{U}$ together with $\mathrm{K} / \mathrm{Rb} \approx 450$ and $\mathrm{K} / \mathrm{Ba} \approx 30$ [Philpotts and Schnetzler, 1970]. Most estimates of the average Sr concentration in crustal materials lie in the range $320-400 \mathrm{ppm}$ [Taylor, 1964; Hurley, 1968a, b; Larimer, 1971; Taylor, 1977] typically with an average value of $\sim 370 \mathrm{ppm}$ which we have used.

Average Sm and Nd concentrations seem to be approximately the same in both upper and lower crustal rocks. We have thus used $\mathrm{Nd}=26 \mathrm{ppm}$ from Shaw et al. [1976]. Average continental crustal materials typically have $f_{\mathrm{sm} / \mathrm{Nd}} \approx-0.4$ [McCulloch and Wasserburg, 1978], and this gives $\mathrm{Sm}=5$ ppm in the total crust.

\section{RESULTS FOR MODEL I}

We now will attempt to evaluate the parameters of this model for both $\mathrm{Rb}$-Sr and Sm-Nd by first only considering estimates from observed $\epsilon$ values and $f$ values (Table 3 ) using (26). These parameters are more directly known than the concentrations in the various reservoirs. The enrichment factor for Rb-Sr in the MORB source is estimated to be $s f_{2}{ }^{\mathrm{Rb} / \mathrm{Sr}}=$ -0.9. As $f_{2}{ }^{\mathrm{Rb} / \mathrm{sr}}$ is close to the limit of -1 , it is therefore not subject to substantial error. The mean $\epsilon_{\mathrm{Sr}}$ value of MORB is -27 . These values give a reliable estimate of the mean age of the MORB source today ( $\bar{t}=1.8$ aeons). If the rate of production of crust were constant over 4.5 aeons, then $\bar{t}=T_{0} / 2=2.3$ aeons. As $\bar{t}$ is much less than 2.3 aeons, this shows that if model $I$ is valid, the rate of crustal and mantle formation was much greater in the time subsequent to 1.8 aeons in comparison with the rate between 1.8 and 4.55 aeons. It is of interest to note that for a uniform rate of crustal formation, we calculate $T_{0}=3.6$ aeons the age of the oldest known terrestrial rocks. This model suggests a low initial rate of crustal formation. The MORB show a range of $f_{2}{ }^{\mathrm{Sm} / \mathrm{Nd}}$ from $\sim 0$ to +0.4 , but their average $\epsilon_{\mathrm{Nd}, 2}=+10$ is well defined. As the model has the same value of $\bar{t}$ for different species, we therefore use the mean age of 1.8 aeons from the $\mathrm{Rb}-\mathrm{Sr}$ data to arrive at a selfconsistent estimate of $f_{2} \mathrm{Sm} / \mathrm{Nd}=+0.225$. This compares well with the estimate given in Table 3 of $f_{2} \mathrm{sm} / \mathrm{Nd}=+0.22$. For the continental crust the only parameter for which we have a reliable estimate is $\int_{3} \mathrm{~S}_{\mathrm{m}} / \mathrm{Nd}=-0.4$. With our estimate of the mean age $\bar{t}=1.8$ aeons this gives $\epsilon_{\mathrm{Nd}, 3}(0)=-17.8$, which is in the middle of the range of values reported for Canadian shield composite samples and sedimentary rocks by $\mathrm{McCulloch}$ and Wasserburg [1978]. Reliable estimates of $\epsilon_{\mathrm{Sr}, 3}$ and $f_{3}{ }^{\mathrm{Rb} / \mathrm{Sr}}$ for the continental crust are much harder to obtain directly, owing to the strong upward concentration of $R \mathbf{b}$ in the crust as discussed previously. Estimates of $f^{R b / S_{r}}$ for the upper crust give $f^{\mathrm{Rb} / \mathrm{Sr}} \sim+10$ [McCulloch and Wasserburg, 1978]. However, average continental runoff shows $\epsilon_{\mathrm{Sr}}(0)=+163$ [Veizer and Compston, 1974], which would yield $f_{3}{ }^{\mathrm{Rb} / \mathrm{sr}}=+5.4$ if $\bar{t}=1.8$ aeons. Strontium has a short residence time in sea water $\left(4 \times 10^{6} \mathrm{yr}\right)$, and if we assume that the sea water $\left(\epsilon_{\mathrm{Sr}}(0)=\right.$ +65) [Papanastassiou et al., 1970; Hildreth and Henderson, 1971] represents average crust, then we get $f_{3} \mathrm{Rb} / \mathrm{Sr}=+2.16$. This is identical to our estimate in Table 6 based on a crustal model with a granulite facies lower crust. However, the similarity may be fortuitous, as $\mathrm{Sr}$ in seawater may be affected by isotope exchange with oceanic crust during hydrothermal convection within oceanic ridges [Spooner, 1976]. The self-consistent values of the model parameters discussed above are given in Table 7.

Assuming that the Bay of Islands data are a proper representation of the MORB source of 0.5 aeon ago (Table 3), we may calculate the various model parameters at that time. For Rb-Sr using $f_{2}{ }^{R b / S r}=-0.9$ from Table 7 and the observed $\epsilon_{\mathbf{S r}, 2}$ $=-19.3$, we obtain $\bar{t}=1.3$ aeons at 0.5 aeon ago. Similarly, for $\mathrm{Sm}-\mathrm{Nd}$ using the observed $\epsilon_{\mathrm{Nd}, 2}=+7.6$ and the parameters in Table 7, we get $\vec{t}=1.4$ aeons. Equation (27) gives the variation of the mean age with time. Since $d \bar{t} / d \tau=1-\bar{t}(d \ln M / d \tau)$ $\leq 1$, it follows that $\bar{t}$ (today) $-\bar{t}(0.5$ aeon ago $) \leq 0.5$. For $\mathrm{Rb} /$ Sr this difference is 0.5 , implying that $d M / d \tau \cong 0$ for the last $500 \mathrm{~m}$.y. For $\mathrm{Sm} / \mathrm{Nd}$ this difference is 0.4 , implying that ( $d$ ln $M / d \tau)=0.11$ aeon $^{-1}$ for the last $500 \mathrm{~m} . \mathrm{y}$., which is half of the 


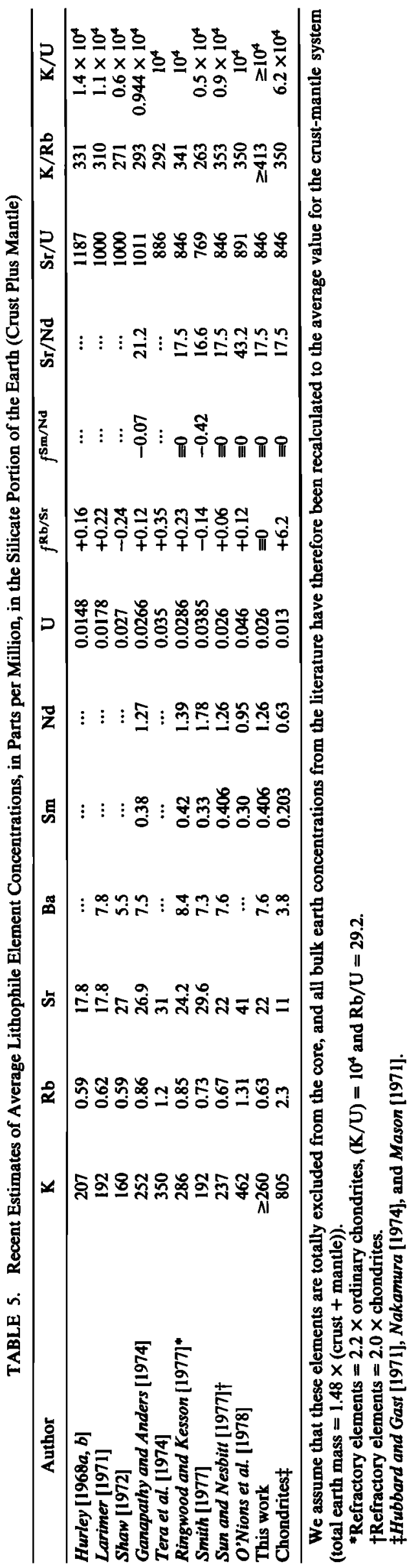

average growth rate of the crust $\left[\left(1 / T_{0}\right)=0.22\right.$ aeon $\left.^{-1}\right]$. However, if the mean age measured 0.5 aeon ago was 1.5 aeons instead of 1.3 or 1.4 aeons, then $(d M / d \tau)$ for the last 0.5 aeon would be equal to the average growth rate of the crust. Thus the value for $(d M / d \tau)$ during the last 0.5 aeon is very sensitive to small differences in the mean ages. No firm conclusion can be drawn, but the data suggest that the average growth rate of the continents and the rate of differentiation of the mantle for the last 0.5 aeon is less than half of the average value over the history of the earth.

We now turn to the problem of evaluating the concentrations of $\mathrm{Rb}, \mathrm{Sr}, \mathrm{Nd}$, and $\mathrm{Sm}$ and the masses of the various reservoirs. The concentrations used for the undepleted mantle and the crust are those from Tables 5 and 6, respectively, except for the $\mathrm{Rb}$ concentration in the crust, which will be calculated in the following. These parameters are given in Table 7. From conservation of mass and species we have as before that $C_{i, 1}=C_{i, 2}(1-x)+C_{i, 3} x$, where $x=M_{2} /\left(M_{2}+M_{3}\right)$ for both stable and radioactive isotopes. This together with the definition of $f_{j}^{r / s}$ (equation (17)) leads to the following equation that relates the masses of reservoirs 2 and 3 to the $f$ values of 2 and 3 and the concentrations of the stable isotope in 1 and 3:

$$
\frac{M_{3}(\tau)}{M_{2}(\tau)+M_{3}(\tau)}=\frac{f_{2}^{r / s}(\tau) C_{s, 1}(\tau)}{\left[f_{2}^{r / s}(\tau)-f_{3}{ }^{r / s}(\tau)\right] C_{s, 3}(\tau)}
$$

This equation holds for any model as long as reservoirs 2 and 3 are derived from the reference reservoir 1 . For model I the left-hand side of (78) must be equal to the degree of melting $F=M_{3}(\tau) /\left[M_{2}(\tau)+M_{3}(\tau)\right]$. The degree of melting must be the same for all species, so (78) gives us a relation between the $f$ values for the $\mathbf{R b} / \mathrm{Sr}$ and the $\mathrm{Sm} / \mathrm{Nd}$ system. From the values of $f_{2} \mathrm{sm} / \mathrm{Nd}, f_{3}^{\mathrm{sm} / \mathrm{Nd}}, C_{\mathrm{Nd}, 1}$, and $C_{\mathrm{Nd}, 3}$ in Table 7, it follows that $F=0.0174$. Using this value and the mass of the total continental crust given in Table 2, we get that the mass of the depleted mantle today is $127 \times 10^{25}$ grams. This corresponds to approximately the upper $650 \mathrm{~km}$ of the mantle or $\sim 1 / 3$ of the mass of the mantle. As was noted previously, the values of $f_{3}{ }^{\mathrm{Rb} / \mathrm{Sr}}$ and $C_{\mathrm{Rb}, 3}$ are not well known. We therefore use (78), the values of $f_{2}{ }^{\mathrm{Rb} / \mathrm{Sr}}, C_{\mathrm{Sr}, 1}$, and $C_{\mathrm{Sr}, 2}$ from Table 7 , and $F=$ 0.0174 as estimated above to calculate $f_{3}{ }^{\mathrm{Rb} / \mathrm{Sr}}=2.18$ and $C_{\mathrm{Rb}, 3}$ $=33.7$. This is identical to estimates made previously of these parameters, and it gives $\epsilon_{\mathrm{Sr}, 3}(0)=+65.5$ if $\bar{t}=1.8$ aeons. From this information we can calculate the concentrations of all the elements in reservoir 2 and the bulk distribution coefficients using (11) and (12). The complete set of self-consistent parameters for $\mathbf{R b}, \mathbf{S r}, \mathbf{S m}$, and $\mathrm{Nd}$ are given in Table 7 for model $\mathrm{I}$. The calculated bulk distribution coefficients agree to better than a factor of 2 with garnet peridotite bulk distribution coefficients estimated from the mineral melt distribution coefficients from Table $4\left(D_{\mathrm{Rb}} \approx 0.0025, D_{\mathrm{Sr}} \approx 0.033, D_{\mathrm{Nd}} \approx 0.044\right.$, and $D_{\mathrm{Sm}} \approx 0.080$ for small degrees of melting of garnet peridotite).

This approach can also be extended to include other elements by using (11) and (12). We briefly investigate the consequences of this model for $K, U$, and $B a$, since these are strongly incompatible elements with $D_{i} \approx 0$. If $D_{1}=0$, then $C_{i, 3} / C_{i, 1}=57$ for $F=0.0174$, which is the maximum enrichment we may have for this model. Bulk distribution coefficients estimated in Table 4 for these elements are $D_{\mathrm{K}}=\mathbf{0 . 0 0 2}$, $D_{\mathrm{Ba}}=0.0014$, and $D_{\mathrm{U}}=0.001$, and these values will be used for the calculations. The concentrations for reservoirs 1 and 3 are obtained from Tables 5 and 6 . The concentration of $K$ in the total crust $(1.5 \mathrm{wt} . \%)$ is used with the above mentioned pa- 


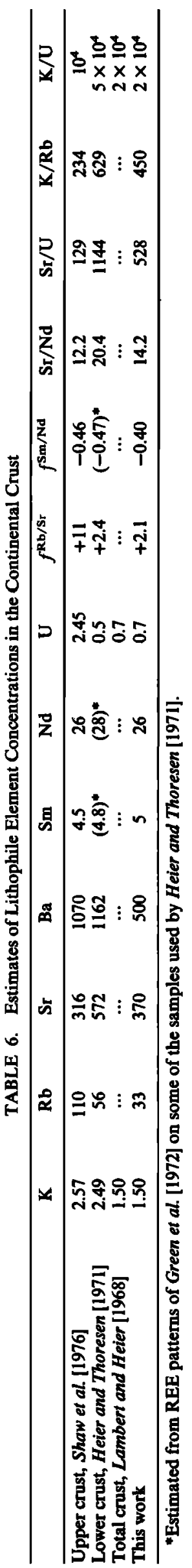

rameters to get $C_{\mathrm{K}, 1}=290 \mathrm{ppm}$ and $C_{\mathrm{K}, 2}=30 \mathrm{ppm}$. It follows then that the bulk earth $K / \mathbf{R b}$ ratio is $\mathbf{4 6 0}$ and that this ratio is 680 in the depleted mantle. This ratio for the depleted mantle still seems somewhat low, as $K / R b \sim 1000$ for MORB, but this difference may be accounted for by only increasing $D_{\mathrm{K}}$ from 0.002 to 0.003 . For $\mathrm{Ba}$ and $\mathrm{U}$ the concentrations in the undepleted mantle are considered to be better established than for K (Table 5). Using (11), we get $C_{\mathrm{Be}, 3}=405 \mathrm{ppm}$ and $C_{\mathrm{U}, 3}=1.4 \mathrm{ppm}$, which compare reasonably well with the estimates given for the average total crust in Table 6. The calculated concentrations in the depleted reservoir are $C_{\mathrm{Ba}, 2}=0.57$ ppm and $C_{\mathrm{U}, 2}=1.4 \mathrm{ppb}$. Existing data for $\mathrm{K}, \mathrm{Rb}$, and $\mathrm{Ba}$ are thus reasonably consistent with model $I$.

We will now consider the possibility that undifferentiated material is being mixed with the depleted mantle by the mechanism described by (29)-(33). In this case, $\beta F=M_{3}(\tau)$ / $\left(M_{2}(\tau)+M_{3}(\tau)\right)$. From the value of $f_{2}{ }^{\mathrm{Rb} / \mathrm{S} r}=-0.9$ from Table 7 we get from (35) that $\beta>0.9$. This means that the amount of undifferentiated material that may be mixed with the depleted mantle is less than $10 \%$. Considering only the surface area covered by continents and oceans today, we would expect that $\beta=0.42$ using the surface areas given by Ronov and Yaroshevsky [1976]. This suggests that if model I is valid, there must be some mechanism for efficient addition to continents of melt fractions from undifferentiated material that differentiates beneath oceans. As was discussed previously, we may also consider the case $\beta<1$ to be analogous to refluxing of crust to depleted mantle in a generalized version of model $I$. This shows that only $10 \%$ of the total amount of material added to the crust may have been subducted back to the depleted mantle.

\section{RESULTS FOR MODEL II}

We now evaluate the present day parameters for this model. As for model I, we again start out with the most reliable values given in Table 3. Substituting $\epsilon_{\mathrm{Sr}, 2}=-27$ and $f_{2}{ }^{\mathrm{Rb} / \mathrm{Sr}}$ $=-0.9$ into (63) gives $\bar{t}_{\mathrm{Rb} / \mathrm{sr}}=1.8$ aeons. It follows for this model that the mean mass age of the continents is substantially less than $\left(T_{0} / 2\right)=2.3$ aeons. This clearly implies that the rate of growth of the continental crust yields a mass growth curve which accelerates with time; i.e., the crustal growth rate for the past 2 aeons being much higher than for the period from 4.5 to 3.6 aeons. This result can be modified only if the bulk earth parameters for Rb-Sr given in the Appendix were substantially altered. To obtain self-consistent values for the Sm-Nd system, we note that the possible fractional range of $f^{\mathrm{Sm} / \mathrm{Nd}}$ values for the depleted mantle is substantially larger than the corresponding fractional range of $f^{\mathbf{R b} / \mathrm{sr}}$ and the range in possible crustal $\epsilon_{\mathrm{Nd}}$ values is also large, thus placing only rather broad bounds on the value of $\bar{t}_{\mathrm{Sm} / \mathrm{Nd}}$. Stricter bounds of $f^{\mathrm{sm} / \mathrm{Nd}}$ are placed by using $\bar{t}_{\mathrm{Rb} / \mathrm{Sn}}$, since $\bar{t}_{M, 3}$ $\approx \bar{t}_{\mathrm{Sm} / \mathrm{Nd}} \leq \bar{t}_{\mathrm{Rb} / \mathrm{sr}}=1.8$ aeons. So from (63) we get $f_{2}{ }^{\mathrm{sm} / \mathrm{Nd}} \geq$ 0.225 , and the direct observational upper bound from the Appendix is $f_{2} \mathrm{sm} / \mathrm{Nd} \leq 0.3$. Note that for model II, knowledge of the present day $f_{2}$ values explicitly determines the quantity $\alpha_{r / s}$ $\left(T_{0}\right)=\left[\left(d_{r}-d_{s}\right) M_{3}\left(T_{0}\right) / M_{2}(0)\right]$ using (50). Using $f_{2}^{\mathrm{Rb} / \mathrm{Sr}}\left(T_{0}\right)=$ -0.9 for the present value, we obtain $\alpha_{\mathrm{Rb} / \mathrm{sr}}\left(T_{0}\right)=+2.30$. This shows that $f_{2}{ }^{\mathrm{Rb} / \mathrm{Sr}}=\exp \left[-\alpha_{\mathrm{Rb} / \mathrm{Sr}}(\tau)\right]-1$ is in the strongly nonlinear range. In contrast, $0.225 \leq f_{2}{ }^{\mathrm{sm} / \mathrm{Nd}} \leq 0.3$, which implies that $-0.264 \leq \alpha_{\mathrm{Sm} / \mathrm{Nd}}\left(T_{0}\right) \leq-0.203$, so that $f_{2} \mathrm{Sm} / \mathrm{Nd}$ is determined to within $10 \%$ by the first-order expansion over the history of the earth. This contrast between Rb-Sr and Sm-Nd is different from that of model $I$ and reflects the fundamental 
TABLE 7. A Self-Consistent Set of Parameters for Model I

\begin{tabular}{|c|c|c|c|c|c|c|c|c|c|}
\hline Reservoir $j$ & $C_{\mathrm{Rb}, J}$ & $C_{\mathbf{S r}_{r},}$ & $f_{J}^{\mathbf{R b} / \mathbf{S r}}$ & $\epsilon_{\mathrm{Sr}_{2},}(0)$ & $C_{\mathrm{sm}, j}$ & $C_{\mathrm{Nd}, J}$ & $f_{j}^{\mathrm{Sm} / \mathrm{Nd}}$ & $\epsilon_{\mathbf{N d}, f^{(0)}}$ & $M_{J}^{\text {(loday) }}, \mathrm{g}$ \\
\hline $\begin{array}{l}\text { Continental crust } j=3 \\
\text { Depleted mantle } j=2 \\
\text { Undepleted mantle } j=1\end{array}$ & $\begin{array}{l}33.7 \\
0.044 \\
0.63\end{array}$ & $\begin{array}{l}370 \\
15.8 \\
22\end{array}$ & $\begin{array}{l}2.18 \\
-0.9 \\
\equiv 0\end{array}$ & $\begin{array}{l}65.5 \\
-27 \\
=0\end{array}$ & $\begin{array}{l}5.0 \\
0.32 \\
0.406\end{array}$ & $\begin{array}{l}26 \\
0.82 \\
1.26\end{array}$ & $\begin{array}{l}-0.4 \\
0.225 \\
=0\end{array}$ & $\begin{array}{c}-17.8 \\
10 \\
=0\end{array}$ & $\begin{array}{l}2.256 \times 10^{25} \\
127.4 \times 10^{25} \\
273.7 \times 10^{25}\end{array}$ \\
\hline
\end{tabular}

$\bar{t}=1.8$ aeons; $F=0.0174 ; \beta=1 ; D_{\mathrm{Rb}}=0.0013 ; D_{\mathrm{Sr}_{\mathrm{r}}}=0.043 ; D_{\mathrm{Nd}}=0.032 ; D_{\mathrm{Sm}_{\mathrm{m}}}=0.065$.

Concentrations are given in parts per million.

differences between the two models. The values of $\alpha_{\mathrm{kb} / \mathrm{sr}}$ and $\alpha_{\mathrm{Sm} / \mathrm{Nd}}$ may be used to find $M_{2}(0)$ and $\left(d_{r}-d_{s}\right)$ using the value of $M_{3}\left(T_{0}\right)$ from Table 2. If we assume that the whole mantle is involved in crust formation, then $\left[M_{3}\left(T_{0}\right) / M_{2}(0)\right]=0.00448$, which implies that $d_{\mathrm{Rb}}-d_{\mathrm{Sr}}=513$ and $d_{\mathrm{Sm}}-d_{\mathrm{Nd}}=-46$. We now assume that reasonable values for the degree of melting $F$ would be in the range from 0.5 to $5 \%$ by mass. Using the bulk distribution coefficients from Table 3 , we find a range of $\left(d_{\mathrm{Rb}}\right.$ $-d_{\mathrm{sr}}$ ) from 7 to 108 for Rb-Sr (equation (50)). This implies that $\left[M_{3}\left(T_{0}\right) / M_{2}(0)\right]$ should be in the range from 0.021 to 0.33 using $\alpha_{\mathrm{Rb} / \mathrm{sr}}=2.3$. Similarly, we get that $\left(d_{\mathrm{Sm}}-d_{\mathrm{Nd}}\right)$ must be in the range from -8.7 to -3 , and using the range of $\alpha_{\mathrm{Sm} / \mathrm{Nd}}$ given previously implies that $0.023 \leq\left[M_{3}\left(T_{0}\right) / M_{2}(0)\right] \leq 0.081$. We may also estimate $M_{3}\left(T_{0}\right) / M_{2}(0)$ from (78) using $C_{\mathrm{Nd}, 1}=$ $1.26 \mathrm{ppm}$ and $C_{\mathrm{Nd}, 3}=26 \mathrm{ppm}$. Since $f_{3} \mathrm{sm} / \mathrm{Nd}=-0.4$ and 0.225 $\leq f_{2}{ }^{\mathrm{sm} / \mathrm{Nd}} \leq 0.3$ as discussed previously, it follows from (78) that $0.0174 \leq\left[M_{3}\left(T_{0}\right) / M_{2}(0)\right] \leq 0.0208$. From these estimates the most reasonable choice seems to be $M_{3}\left(T_{0}\right) / M_{2}(0)=0.020$ \pm 0.003 , and this gives $M_{2}\left(T_{0}\right)=110.5 \times 10^{25}$ grams, which is $28 \%$ of the mantle. Using this value for $M_{3}\left(T_{0}\right) / M_{2}(0)$ in (78) gives $f_{2} \mathrm{Sm} / \mathrm{Nd}=+0.281$ and thus $\alpha_{\mathrm{Sm} / \mathrm{Nd}}=-0.248$. From (63) it now follows that $i_{\mathrm{Sm} / \mathrm{Nd}}=1.44$ aeons, which together with $f_{3}{ }^{\mathrm{Sm} / \mathrm{Nd}}=-0.4$ gives $\epsilon_{\mathrm{Nd}, 3}=14.3$. Similarly, using (78) for $\mathbf{R b}$ Sr with $f_{2}^{\mathrm{Rb} / \mathrm{Sr}}=-0.9,\left[M_{3}\left(T_{0}\right) / M_{2}(0)\right]=0.02, C_{\mathrm{Sr}, 1}=22 \mathrm{ppm}$, and $C_{\mathrm{Sr}, 3}=370 \mathrm{ppm}$, we get $f_{3}{ }^{\mathrm{Rb} / \mathrm{sr}}=+1.78, C_{\mathrm{Rb}, 3}=29.4 \mathrm{ppm}$, and since $\bar{t}_{\mathrm{Rb} / \mathrm{sr}}=1.8$ aeons it also follows that $\epsilon_{\mathrm{Sr}, 3}=+53.4$.

We have now determined a self-consistent set of $f$ and $\epsilon$ values for model II, which are given in Table 8. From the values $f_{2}^{r / s}$ and $f_{3}{ }^{r / s}$ for $\mathrm{Sm} / \mathrm{Nd}$ and $\mathrm{Rb} / \mathrm{Sr}$ together with $\left[M_{3}\left(T_{0}\right) /\right.$ $\left.M_{2}(0)\right]=0.020$ we can, by using (50) and (51), determine all the $d$ values which are given in Table 8 . Since $D_{\mathrm{Rb}}>0$, it follows from the value we calculated for $d_{\mathrm{Rb}}=135.5$ that $F<$ 0.0076. Choosing $D_{\mathrm{Rb}}=0.0025$ from Table 4 gives $F=0.005$. Using this value of $F$, we may calculate $D_{\mathrm{Sr}}, D_{\mathrm{Nd}}$, and $D_{\mathrm{Sm}}$ (Table 8). From the $d$ values listed in Table 8 and the concentrations of the undepleted reservoir we may now calculate the concentrations of these elements in the depleted reservoir. A complete set of self-consistent parameters for $\mathrm{Rb}, \mathrm{Sr}, \mathrm{Sm}$, and Nd are given in Table $\mathbf{8}$ for model II. The parameters for $\mathbf{R b}$ imply that the concentration of $R \mathbf{b}$ in new additions to the crust has changed from $86 \mathrm{ppm}$ initially to $6 \mathrm{ppm}$ today giving an average concentration today of $\sim 30 \mathrm{ppm}$. This large change of $\mathbf{R b}$ concentration in the crust over geologic time does not appear supportable from the existing data. The magnitude of this time dependence is not changed by any choice of parameters so long as $f_{2}{ }^{\mathbf{R b} / \mathbf{S r}}$ is close to its lower limit of -1 .

We now turn our attention to see what the data can tell us about the time evolution of the continental crust. The simplest growth model would be $\left(d M_{3} / d \tau\right)=$ const over the history of the earth. Using this assumption, we get $\bar{t}_{\mathrm{Sm} / \mathrm{Nd}}-\bar{t}_{M, 3}=-0.09$ aeon from (66) with $\tau=4.5$ aeons and $\alpha_{\mathrm{Sm} / \mathrm{Nd}}=-0.248$, so since $\bar{t}_{\mathrm{Sm} / \mathrm{Nd}}=1.44$ aeons, it follows that $\bar{t}_{M, 3} \approx 1.5$ aeons. However, since $\bar{t}_{M, 3} \leq \bar{t}_{\mathrm{Rb} / \mathrm{Sr}}=1.8$ aeons $<\left(T_{0} / 2\right)$, this would require that the crust started to form late. The longest time compatible with a uniform growth may be determined from (71) and (72). For Rb-Sr we get 2.7 aeons and for Sm-Nd we get 3.0 aeons for the longest time compatible with a constant growth rate of the crust using the $f$ and $\epsilon$ values for reservoir 2 given in Table 3. These are both unrealistically low values, so we must conclude that a uniform growth rate can hardly explain the data. It is, however, clear that this model also requires the dominant parts of the continents to have formed late in the earth's history.

From the Bay of Islands data [Jacobsen and Wasserburg, 1979], similar estimates can be made for the depleted mantle 0.5 aeon ago using the values given in Table 3 . Our estimates of the enrichment factors for the Bay of Islands source are $f_{2} \mathrm{Rb} / \mathrm{sr}$ $=-0.9$ and $f_{2} \mathrm{Sm} / \mathrm{Nd} \approx+0.2$ (Table 3). For Rb-Sr using $\epsilon_{\mathrm{Sr}, 2}=$ -19.3 , we obtain $\bar{t}_{\mathrm{Rb} / \mathrm{Sr}}=1.3$ aeons at 0.5 aeon ago, which indicates that $\left(d M_{3} / d \tau\right) \approx 0$ for the last $500 \mathrm{~m} . \mathrm{y}$. as in model I. For Sm-Nd using $\epsilon_{\mathrm{Nd}, 2}=+7.6$, we obtain by using the estimate of the present day $f_{2}^{\mathrm{Sm} / \mathrm{Nd}}$ of +0.28 (Table 8) that $\bar{t}_{\mathrm{Sm} / \mathrm{Nd}}$ $\approx 1.1$ aeons. From (66) we get $\bar{t}_{\mathrm{sm} / \mathrm{Nd}}-\bar{t}_{M, 3}=-0.08$ at 0.5 aeon ago, so it follows that $\bar{t}_{M, 3} \approx 1.2$ aeons at that time for this model. This is only slightly lower than the value obtained for model I.

\section{Discussion OF THE MODELS AND CONClusions}

The basic transport equations for the earth differentiation models shown in Figure 1 give simple results when solved for arbitrary mass growth curves $M_{,}(\tau)$ for the continental crust $(j=3)$ and the depleted mantle $(j=2)$. The solution for model $I$ is

$$
\epsilon_{d_{J}}^{*}(\tau)=\frac{Q_{d}^{*}(\tau) f_{j}^{p / s}}{M_{(}(\tau)} \int_{0}^{\tau} M_{(}(\xi) \exp [\lambda(\tau-\xi)] d \xi
$$

where

$$
Q_{d}^{*}(\tau)=10^{4} \lambda\left\lceil\frac{N_{r, 1}(\tau)}{N_{d, 1}(\tau)}\right]
$$

and $f_{j}^{r / s}$ is the enrichment factor, which is constant for all time. The mean age $\bar{t}_{s,}$ of stable isotopes is equal to the mean age of the mass of $\dot{j}, \bar{t}_{M_{J}}=\int_{0}{ }^{\tau}\left[M_{\lambda}(\xi) / M_{\lambda}(\tau)\right] d \xi$. For long-lived isotopes $\left(\lambda^{-1} \gg 4.5\right.$ aeons), $\epsilon_{d_{j}}{ }^{*}=Q_{d}{ }^{*} f^{r / s} \bar{t}_{M_{j}}$, and $Q_{d}{ }^{*} \simeq$ const. Knowledge of $\epsilon_{d_{v}}{ }^{*}$ and $f_{j}^{r / s}$ at a single time fixes $\bar{t}_{M_{v}}$. The mean age shows the relationship $(d \bar{t} / d \tau)=1-\bar{t}\left(d \ln M_{j} /\right.$ $d \tau)$, so if $M_{,}(\tau)$ and $f_{f}^{r / s}$ are known, then $\bar{t}_{M_{J}}$ and $\epsilon_{d_{J}}{ }^{*}(\tau)$ are known.

For model II which has continuous fractionation in the source reservoir the concentrations are functions of time, and we get

$$
\begin{gathered}
\epsilon_{d, 2}{ }^{*}(\tau)=Q_{d}{ }^{*}(\tau) \int_{0}^{\tau} f_{2}^{r / s}(\xi) \exp [\lambda(\tau-\xi)] d \xi \\
\epsilon_{d, 3}{ }^{*}(\tau)=\epsilon_{d, 2}{ }^{*}(\tau) \frac{f_{3}^{r / s}(\tau)}{f_{2}^{r / s}(\tau)}
\end{gathered}
$$


TABLE 8. A Self-Consistent Set of Parameters for Model II at $\tau=T_{0}$ (Today)

\begin{tabular}{|c|c|c|c|c|c|c|c|c|c|}
\hline Reservoir $j$ & $C_{\mathrm{Rb}, J}$ & $C_{\mathrm{Sr}, \mathrm{J}}$ & $f_{J}^{\mathrm{Rb} / \mathbf{S}_{\mathbf{r}}}$ & $\epsilon_{\mathbf{S}_{\mathbf{r}, y}}{ }^{*}$ & $C_{\mathrm{Sm}, J}$ & $C_{\mathrm{Nd}, J}$ & $f_{j}^{S m / N d}$ & $\epsilon_{\mathrm{Nd}_{\mathbf{v}}}{ }^{*}$ & $\boldsymbol{M}_{\boldsymbol{p}} \mathrm{g}$ \\
\hline $\begin{array}{l}\text { Continental crust } j=3 \\
\text { Depleted mantle } j=2 \\
\text { Undepleted mantle } j=1\end{array}$ & $\begin{array}{l}29.4 \\
0.041 \\
0.63\end{array}$ & $\begin{array}{l}370 \\
14.5 \\
22\end{array}$ & $\begin{array}{l}1.78 \\
-0.9 \\
=0\end{array}$ & $\begin{array}{l}53.4 \\
-27 \\
=0\end{array}$ & $\begin{array}{l}5.0 \\
0.29 \\
0.406\end{array}$ & $\begin{array}{l}26 \\
0.74 \\
1.26\end{array}$ & $\begin{array}{l}-0.4 \\
0.281 \\
=0\end{array}$ & $\begin{array}{l}-14.3 \\
10 \\
=0\end{array}$ & $\begin{array}{l}2.256 \times 10^{25} \\
110.5 \times 10^{25} \\
290.6 \times 10^{25}\end{array}$ \\
\hline
\end{tabular}

$\tau_{\mathrm{Rb} / \mathrm{Sr}}=1.8 \mathrm{aeons} ; \tau_{\mathrm{Sm} / \mathrm{Nd}}=1.44 \mathrm{aeons} ; T_{M, 3}=1.5$ aeons; $M_{3}\left(T_{0}\right) / M_{2}(0)=0.020 ; d_{\mathrm{Rb}}=135.5 ; d_{\mathrm{Sr}}=20.5 ; d_{\mathrm{Nd}}=26.6 ; s_{\mathrm{Sm}}=16.2 ; \alpha_{\mathrm{Rb} / \mathrm{Sr}}\left(T_{0}\right)=$ $+2.30 ; \alpha_{\mathrm{Sm} / \mathrm{Nd}}\left(T_{0}\right)=-0.248 ; F=0.005 ; D_{\mathrm{Rb}}=0.0025 ; D_{\mathrm{Sr}}=0.044 ; D_{\mathrm{Nd}}=0.033 ; D_{\mathrm{Sm}}=0.057$.

Concentrations are given in parts per million.

$$
\begin{aligned}
& f_{2}^{r / s}(\tau)=\left[\frac{M_{2}(\tau)}{M_{2}(0)}\right]^{\left(d_{r}-d_{s}\right)} \\
& \frac{f_{2}{ }^{r / s}(\tau)}{f_{3}{ }^{r / s}(\tau)}=1-\left[\frac{M_{2}(\tau)}{M_{2}(0)}\right]^{\left(-d_{s}\right)}
\end{aligned}
$$

Define $\bar{t}_{r / s} \equiv \int_{0}{ }^{r}\left[f_{2}{ }^{r / s}(\xi) / \int_{2}{ }^{r / s}(\tau)\right] d \xi$. Then for long-lived isotopes we have $\epsilon_{d_{v}}{ }^{*}(\tau)=Q_{d}{ }^{*} f_{j}^{r / s}(\tau) \bar{t}_{r / s}$, where $\bar{t}_{r / s}$ is the time required to generate $\epsilon_{d j}{ }^{*}$ with the present value of $f_{j}^{r / s}$. Note that $\bar{t}_{r / s}$ depends on the parent-daughter system and is in general different from $\bar{t}_{M, 3}$. The difference is given by

$$
\bar{t}_{r / s}-\bar{t}_{M, 3} \approx \frac{\left(d_{r}-d_{s}\right)}{2 M_{3}(\tau) M_{2}(0)} \int_{0}^{\tau} M_{3}(\xi)\left[M_{3}(\tau)-M_{3}(\xi)\right] d \xi
$$

for small $\left[\left(d_{r}-d_{s}\right) / M_{2}(0)\right]$. Decay systems with small $\left(d_{r}-d_{s}\right)$ may be used to estimate $\bar{t}_{M, 3}$. These simple expressions may be used to calculate earth models with great facility without requiring a computer calculation.

We first compare the results from models I and II (Tables 7 and 8 ). The mean age of the crust is 1.8 aeons for model $I$ and 1.5 aeons for model II, so a young mean age of the crust is confirmed by both models. Similarly, both models indicate that the rate of growth over the last 0.5 aeon is much less than the average rate of growth. Therefore most of the crust probably formed in the time interval from $\sim 0.5$ to $\sim 3$ aeons ago. Both models also require the depleted mantle complementary to the continental crust to make up about $1 / 3$ of the mantle, which corresponds approximately to the upper $650 \mathrm{~km}$ of the mantle. This does not seem to be compatible with whole mantle convection as discussed by Hager and $O^{\prime}$ Connell [1979]. In future studies it is of importance to arrive at mantle structure models which satisfy both the boundary conditions on mantle convection and isotope geochemistry. The present day $\epsilon$ and $f$ values and the concentration in each reservoir are fairly similar for both models as shown in Tables 7 and 8 . Insofar as the mantle consists of an undepleted reservoir and a depleted reservoir that is complementary to the crust, the above conclusions are basically model independent. Model I indicates a larger degree of melting (1.7\%) than model II $(0.5 \%)$. At the present time both of these values seem to be plausible estimates of the average degree of melting through time. The major difference in the results for the two models is in the composition of new additions to continental crust. Model I predicts that $\epsilon_{\mathrm{Nd}}=\epsilon_{\mathrm{Sr}}=0$ for new additions to the continental crust, and model II predicts that the $\epsilon_{\mathrm{Sr}}$ and $\epsilon_{\mathrm{Nd}}$ of new additions are those of the source of MORB. The fact that island arcs have bulk composition and REE abundances similar to average continental crust and that they usually are found at or near continental margins has led to the hypothesis that the continents grow by accreting island arcs along their margins [Taylor and White, 1965; Ringwood, 1975]. If this is the case, then the Nd isotopic studies reported by DePaolo and Wasserburg [1977] and Hawkesworth et al. [1977] show that new continental material should have $\epsilon_{\mathrm{Nd}}$ values similar to MORB and are thus derived from depleted mantle. This mechanism for continental growth is thus described by model II. However, this model cannot explain why typically most continental crustal materials have $\epsilon_{\mathrm{Nd}} \approx 0$ [DePaolo and Wasserburg, 1976a, b; McCulloch and Wasserburg, 1978; Hamilton et al., 1977, 1978, 1979] throughout the earth's history. While values of $\epsilon \approx 0$ may be obtained at early times for both models, it is not possible to continue production of such materials in more recent geologic time for model II.

In model $I$ the concentrations of stable isotopes in new additions to the crust are the same for all time, however, in model II the concentrations may decrease by over a factor of 10 for highly incompatible elements as $\mathrm{K}, \mathrm{Rb}, \mathrm{Ba}$, and $\mathrm{U}$. There is no evidence for such drastic changes with time. We therefore conclude that model I best describes crust and mantle evolution. Some additions to the continents during the last 1.5 aeons have $\epsilon_{\mathrm{Nd}}>0$ [DePaolo and Wasserburg, 1976a, b], so some new additions to the crust may follow model II. A modified version of model I where it is allowed for mixing of undepleted mantle with depleted mantle shows that this contribution must be less than $10 \%$. This model also shows that less than $10 \%$ of the total continental crust has been refluxed back to the depleted mantle.

Recent isotopic studies of young volcanic rocks have shown that $\epsilon_{\mathrm{Nd}}$ and $\epsilon_{\mathrm{Sr}}$ are strongly correlated in ocean floor and ocean island basalts and selected continental basalts [DePaolo and Wasserburg, 1976b; O'Nions et al., 1977]. This correlation line is assumed to be due to mantle characteristics and has been called the 'mantle array' by DePaolo and Wasserburg [1979a]. Magmas in model I may be mixtures derived from depleted and undepleted mantle and may thus explain the mantle array. Model II does not explain the mantle array unless a range of source reservoirs individually following this model are involved. This would, however, require that some of them be close to undepleted mantle material, but it is not clear that this would satisfy a strict correlation between initial Nd and initial Sr.

Considering the young mean ages derived for the continents, we are left with very little evidence of crust forming very early in the earth's history. Search for old crustal rocks by direct dating has established a low abundance of $\sim 3.6-$ aeon-old crustal rocks and the apparent absence of much older rocks at the surface of the earth. An alternative way of looking for old crust is to look at the residue in the mantle after crust formation. If the pre-3.6-aeon-old crust were buried in the lower crust, then we would still expect to see it in the isotopic systematics of the depleted mantle. The depleted mantle gives a young mean age of $\sim 1.8$ aeons, and this implies either that very little early crust ever formed or that the early crust was destroyed by rapid refluxing into the mantle in the period from 4.5 to 3.6 aeons ago. If the latter is the case, then this would have caused early degassing of the earth's Ar as suggested by ${ }^{40} \mathrm{Ar} /{ }^{36} \mathrm{Ar}$ ratios in the mantle [Ozima, 1975]. The detailed history of this time period must be derived from 
data for ${ }^{40} \mathrm{~K}$ and ${ }^{235} \mathrm{U}$ and perhaps also ${ }^{244} \mathrm{Pu}$ and the extinct 129.

\section{APPENDIX: Present Day Bulk EARTh Values}

The following values are from DePaolo and Wasserburg [1976a, b] and $O$ 'Nions et al. [1977]:

$$
\begin{array}{cl}
\frac{{ }^{87} \mathrm{Sr}\left(T_{0}\right)_{1}}{{ }^{86} \mathrm{Sr}\left(T_{0}\right)_{1}}=0.7045 & \frac{{ }^{87} \mathrm{Rb}\left(T_{0}\right)_{1}}{{ }^{86} \mathrm{Sr}\left(T_{0}\right)_{1}}=0.0827 \\
\frac{{ }^{143} \mathrm{Nd}\left(T_{0}\right)_{1}}{{ }^{144} \mathrm{Nd}\left(T_{0}\right)_{1}}=0.511836 & \frac{{ }^{147} \mathrm{Sm}\left(T_{0}\right)_{1}}{{ }^{144} \mathrm{Nd}\left(T_{0}\right)_{1}}=0.1936 \\
Q_{\mathrm{Nd}}{ }^{*}\left(T_{0}\right)=24.74 \text { aeons }^{-1} & Q_{\mathrm{Sr}}{ }^{*}\left(T_{0}\right)=16.70 \text { aeons }^{-1}
\end{array}
$$

The decay constants used are $\lambda\left({ }^{87} \mathrm{Rb}\right)=0.0142$ aeons $^{-1}$ and $\lambda\left({ }^{147} \mathrm{Sm}\right)=0.00654$ aeons $^{-1} . T_{0}=4.55$ aeons.

Acknowledgments. This work has been supported by NSF grant EAR 76-22494 and NASA grant NGL 05-002-188. We wish to thank R. J. O'Connell for his thorough and scholarly analysis of the manuscript, which resulted in several substantial improvements. Supporting and critical discussions with our colleagues $\mathbf{M}$. McCulloch and $\mathbf{R}$. Jeanloz were of great value. We thank the editor, T. J. Ahrens, and the associate editor, J. Hayes, for careful attention to the manuscript and the reviewers, M. J. Drake and G. Wetherill, for their attention to what might be viewed as a difficult manuscript. G. Wetherill pointed out to us that the earth probably looks more like a $\$ 10$ ice cream sundae than an oil refinery with discrete storage tanks. We hope some day to share the $\$ 10$ ice cream sundae with him. Contribution \#3251 (306).

\section{REFERENCES}

Armstrong, R. L., A model for the evolution of strontium and lead isotopes in a dynamic earth, Rev. Geophys. Space Phys., 6, 175-199, 1968.

Benjamin, T. M., R. Heuser, and D. S. Burnett, Solar system actinide abundances, I, Laboratory partitioning between whitlockite, diopsidic clinopyroxene and anhydrous melt (abstract), in Lunar and Planetary Science, vol. 9, pp. 70-77, The Lunar and Planetary Institute, Houston, 1978.

Brooks, C., and S. R. Hart, Rb-Sr mantle isochrons and variations in the chemistry of Gondwanaland's lithosphere, Nature, 271, 220 223, 1978.

Brooks, C., S. R. Hart, A. Hoffman, and D. E. James, Rb-Sr mantle isochrons from oceanic regions, Earth Planet. Sci. Lett., 32, 51-61, $1976 a$.

Brooks, C., D. E. James, and S. R. Hart, Ancient lithosphere: Its role in young continental volcanism, Science, 193, 1086-1094, 1976b.

Consolmagno, G. J., and M. J. Drake, Equivalence of equations describing trace element distribution during equilibrium partial melting, Geochim. Cosmochim. Acta, 40, 1421-1422, 1976.

DePaolo, D. J., Study of magma sources, mantle structure and the differentiation of the earth using variations of ${ }^{143} \mathrm{Nd} /{ }^{144} \mathrm{Nd}$ in igneous rocks, Ph.D. thesis, Calif. Inst. of Technol., Pasadena, 1978.

DePaolo, D. J., and G. J. Wasserburg, Nd isotopic variations and petrogenetic models, Geophys. Res. Lett., 3, 249-252, 1976 a.

DePaolo, D. J., and G. J. Wasserburg, Inferences about magma sources and mantle structure from variations of ${ }^{143} \mathrm{Nd} /{ }^{144} \mathrm{Nd}$, Geophys. Res. Lett., 3, 743-746, 1976b.

DePaolo, D. J., and G. J. Wasserburg, The sources of island arcs as indicated by Nd and $\mathrm{Sr}$ isotopic studies, Geophys. Res. Lett., 4, 465468, 1977.

DePaolo, D. J., and G. J. Wasserburg, Petrogenetic mixing models and Nd-Sr isotopic patterns, Geochim. Cosmochim. Acta, 43, 615$627,1979 a$.

DePaolo, D. J., and G. J. Wasserburg, Nd isotopes in flood basalts from the Siberian Platform and inferences about their mantle sources, Proc. Nat. Acad. Sci. U.S., 76, 3056-3060, $1979 b$.

Eade, K. E., and W. F. Fahrig, Chemical evolutionary trends of continental plates-A preliminary study of the Canadian shield, Bull. Geol. Surv. Can., 179, 1971.

Frey, F. A., and.D. H. Green, The mineralogy, geochemistry, and ori- gin of Iherzolite inclusions in Victorian basanites, Geochim. Cosmochim. Acta, 38, 1023-1059, 1974.

Ganapathy, R. M., and E. Anders, Bulk compositions of the moon and earth estimated from meteorites, Proc. Lunar Sci. Conf. Sth, 1181-1206, 1974.

Gast, P. W., Limitations on the composition of the upper mantle, $J$. Geophys. Res., 65, 1287-1297, 1960.

Green, T. H., A. O. Brunfelt, and K. S. Heier, Rare-earth element distribution and $K / R b$ ratios in granulites, mangerites and anorthosites, Lofoten-Vesteraalen, Norway, Geochim. Cosmochim. Actä, 36, 241-257, 1972.

Griffin, W. L., and V. R. Murthy, Distribution of $\mathrm{K}, \mathrm{Rb}, \mathrm{Sr}$, and $\mathrm{Ba}$ in some minerals relevant to basalt genesis, Geochim. Cosmochim. Acta, 33, 1389-1414, 1969.

Grutzeck, M., S. Kridelbaugh, and D. Weill, The distribution of $\mathbf{S r}$ and REE between diopside and silicate liquid, Geophys. Res. Lett. I, 273-275, 1974.

Hager, B. H., and R. J. O'Connell, Kinematic models of large-scale flow in the earth's mantle, J. Geophys. Res., 84, 1031-1048, 1979.

Hamilton, P. J., R. K. O'Nions, and N. M. Evensen, Sm-Nd dating of Archean basic and ultrabasic volcanics, Earth Planet. Sci. Lett., 36, 263-268, 1977.

Hamilton, P. J., R. K. O'Nions, N. M. Evensen, D. Bridgwater, and J. Allart, Sm-Nd isotopic investigations of the Isua supracrustals, West Greenland: Implications for mantle evolution, Nature, 272, $41-43,1978$

Hamilton, P. J., N. M. Evensen, R. K. O'Nions, and J. Tarney, SmNd systematics of Lewisian gneisses: Implications for the origin of granulites, Nature, 277, 25-28, 1979.

Hart, S. R., and C. Brooks, Rb-Sr mantle evolution models, Carnegie Inst. Wash. Yearb., 69, 426-429, 1970.

Hart, S. R., and C. Brooks, Clinopyroxene matrix partitioning of $\mathbf{K}$, $\mathrm{Rb}, \mathrm{Cs}$, Sr, and Ba, Geomchim. Cosmochim. Acta, 38, 1799-1803, 1974.

Hawkesworth, C. J., R. K. O’Nions, R. J. Pankhurst, P. J. Hamilton, and N. M. Evensen, A geochemical study of island-arc and backarc tholeiites from the Scotia Sea, Earth Planet. Sci. Lett., 36, 253$262,1977$.

Heier, K. S., Rubidium/strontium and strontium-87/strontium-86 ratios in deep crustal material, Nature, 202, 477-478, 1964.

Heier, K. S., Radioactive elements in the continental crust, Nature, 208, 479-480, 1965.

Heier, K. S., A model for the composition of the deep continental crust, Fortschr. Mineral., 50, 174-187, 1973.

Heier, K. S., and J. A. S. Adams, Concentration of radioactive elements in deep crustal material, Geochim. Cosmochim. Acta, 29, 5361, 1965.

Heier, K. S., and J. J. Rogers, Radiometric determination of thorium, uranium, and potassium in basalts and in two magmatic differentiation series, Geochim. Cosmochim. Acta, 27, 137-154, 1963.

Heier, K. S., and K. Thoresen, Geochemistry of high grade metamorphic rocks, Lofoten-Vesterålen, North Norway, Geochim. Cosmochim. Acta, 35, 89-99, 1971.

Hildreth, R. A., and W. T. Henderson, Comparison of ${ }^{87} \mathrm{Sr} /{ }^{86} \mathrm{Sr}$ for seawater strontium and the Eimer and Amend $\mathrm{SrCO}_{3}$, Geochim. Cosmochim. Acta, 35, 235-238, 1971.

Hubbard, N. J., and P. W. Gast, Chemical composition and origin of nonmare lunar basalts, in Proceedings of the Second Lunar Science Conference, vol. 2, pp. 999-1020, MIT Press, Cambridge, Mass., 1971.

Hurley, P. M., Absolute abundance and distribution of $\mathrm{Rb}, \mathrm{K}$ and $\mathrm{Sr}$ in the earth, Geochim. Cosmochim. Acta, 32, 273-283, $1968 a$.

Hurley, P. M., Correction to: Absolute abundance and distribution of $\mathrm{Rb}, \mathrm{K}$, and $\mathrm{Sr}$ in the earth, Geochim. Cosmochim. Acta, 32, 1025$1030,1968 b$.

Jacobsen, S. B., and G. J. Wasserburg, Nd and Sr isotopic study of the Bay of Islands Ophiolite Complex and the evolution of the source of mid-ocean ridge basalts, J. Geophys. Res., 84, this issue, 1979.

Lambert, I. B., and K. S. Heier, The vertical distribution of uranium, thorium, and potassium in the continental crust, Geochim. Cosmochim. Acta, 31, 377-390, 1967.

Lambert, I. B., and K. S. Heier, Geochemical investigations of deepseated rocks in the Australian shield, Lithos, 1, 30-53, 1968 .

Lambert, I. B., and K. S. Heier, Estimates of the crustal abundance of thorium, uranium and potassium, Chem. Geol., 3, 233-238, 1968 b.

Larimer, J. W., Composition of the earth: Chondritic or Achondritic? Geochim. Cosmochim. Acta, 35, 769-786, 1971. 
Loubet, M., N. Shimizu, and C. J. Allègre, Rare earth elements in alpine peridotites, Contrib. Mineral. Petrol., 53, 1-12, 1975.

Mason, B., Handbook of Elemental Abundances in Meteorites, 131 pp., Gordon and Breach, New York, 1971.

McCulloch, M. T., and G. J. Wasserburg, Sm-Nd, and Rb-Sr chronology of continental crust formation, Science, 200, 1003-1011, 1978.

McKay, G. A., and D. F. Weill, Petrogenesis of Kreep, Proc. Lunar Sci. Conf. 7th, 2427-2447, 1976.

Moorbath, S., Age and isotope evidence for the evolution of continental crust, Phil. Trans. Roy. Soc. London, Ser. A, 288, 401-413, 1978.

Morgan, J. W., and J. F. Lovering, Uranium and thorium in some basic and ultrabasic rocks of possible deep-seated origin, in Activation Analysis in Geochemistry and Cosmochemistry, edited by A. $\mathrm{O}$ Brunfelt and E. Steinnes, pp. 445-454, Universitetsforlaget, Oslo, Norway, 1971.

Nakamura, $\mathrm{N}$., Determination of $\mathrm{REE}, \mathrm{Ba}, \mathrm{Fe}, \mathrm{Mg}, \mathrm{Na}$ and $\mathrm{K}$ in carbonaceous and ordinary chondrites, Geochim. Cosmochim. Acta, 38, 757-775, 1974.

O'Nions, R. K., and D. B. Clarke, Comparative trace element geochemistry of Tertiary basalts from Baffin Bay, Earth Planet. Sci. Lett., 15, 436-446, 1972.

O'Nions, R. K., and R. J. Pankhurst, Early Archaean rocks and geochemical evolution of the earth's crust, Earth Planet. Sci. Lett., 38 , 211-236, 1978.

O'Nions, R. K., P. J. Hamilton, and N. M. Evensen, Variations in ${ }^{143} \mathrm{Nd} /{ }^{144} \mathrm{Nd}$ and ${ }^{87} \mathrm{Sr} /{ }^{86} \mathrm{Sr}$ ratios in oceanic basalts, Earth Planet, Sci. Lett., 34, 13-22, 1977.

O'Nions, R. K., N. M. Evensen, P. J. Hamilton, and S. R. Carter Melting of the mantle past and present: Isotope and trace element evidence, Phil. Trans. Roy. Soc. London, 258, 547-559, 1978.

O'Nions, R. K., N. M. Evensen, and P. J. Hamilton, Chemical constraints on the evolution of the earth's crust and mantle (abstract), in Lunar and Planetary Science, vol. 10, pp. 937-949, The Lunar and Planetary Institute, Houston, 1979.

Ozima, M., Ar isotopes and earth-atmosphere evolution models, Geochim. Cosmochim. Acta, 39, 1127-1134, 1975.

Papanastassiou, D. A., G. J. Wasserburg, and D. S. Burnett, Rb-Sr ages of lunar rocks from the Sea of Tranquility, Earth Planet. Sci. Lett., 8, 1-9, 1970.

Patterson, C., Characteristics of lead isotope evolution on a continental scale of the earth, in Isotopic and Cosmic Chemistry, edited by $\mathbf{H}$. Craig, pp. 248-268, North-Holland, Amsterdam, 1964.

Patterson, C., and $M$. Tatsumoto, The significance of lead isotopes in detrital feldspar with respect to chemical differentiation within the earth's mantle, Geochim. Cosmochim. Acta, 28, 1-22, 1964.

Philpotts, J. A., and C. C. Schnetzler, Phenocryst-matrix partition coefficients for $\mathrm{K}, \mathrm{Rb}, \mathrm{Sr}$ and $\mathrm{Ba}$, with applications to anorthosite and basalt genesis, Geochim. Cosmochim. Acta, 34, 307-322, 1970.

Poldervaart, A., Chemistry of the earth's crust, Crust of the Earth, Geol. Soc. Amer. Spec. Pap., 62, 119-144, 1955.

Richard, P., N. Shimizu, and C. J. Allegre, ${ }^{143} \mathrm{Nd} /{ }^{146} \mathrm{Nd}$, a natural tracer, an application to oceanic basalts, Earth Planet. Sci. Lett., 3I, 269-278, 1976.

Ringwood, A. E., Composition and Petrology of the Earth's Mantle, 618 pp., McGraw-Hill, New York, 1975.

Ringwood, A. E., and S. E. Kesson, Basaltic magmatism and the bulk composition of the moon, II, Siderophile and volatile elements in moon, earth and chondrites: Implications for lunar origin, Moon, 16, 425-464, 1977.

Ronov, A. B., and A. A. Yaroshevsky, A new model for the geochemical structure of the earth's crust, Geochem. Int., 13, 89-121, 1976.

Russell, R. D., Evolutionary model for lead isotopes in conformable ores and in ocean volcanics, Rev. Geophys. Space Phys., 10, 529$549,1972$.

Russell, R. D., and D. J. Birnie, A bi-directional mixing model for Pb-isotope evolution, Phys. Earth Planet. Interiors, 8, 158-166, 1974.
Schilling, J. G., Sea-floor evolution: Rare earth evidence, Phil. Trans. Roy. Soc. London, Ser. A, 268, 663-706, 1971.

Schnetzler, C. C., and J. A. Philpotts, Partition coefficients of rareearth elements between igneous matrix material and rock-forming phenocrysts, II, Geochim. Cosmochim. Acta, 34, 331-340, 1970.

Schramm, D. N., and G. J. Wasserburg, Nucleochronologies and the mean age of the elements, Astrophys. J., 162, 57-69, 1970.

Shaw, D. M., Trace element fractionation during anatexis, Geochim. Cosmochim. Acta, 34, 237-243, 1970.

Shaw, D. M., Development of the early continental crust, I, Use of trace element distribution coefficient models for the protoarchaean crust, Can. J. Earth Sci., 9, 1577-1595, 1972.

Shaw, D. M., G. A. Reilly, J. R. Muysson, G. E. Pattenden, and F. E. Campbell, The chemical composition of the Canadian Precambrian shield, Can. J. Earth Sci., 4, 829-854, 1967.

Shaw, D. M., J. Dostal, R. R. Keays, Additional estimates of continental surface Precambrian shield composition in Canada, Geochim. Cosmochim. Acta, 40, 73-83, 1976.

Shimizu, N., An experimental study of the partitioning of $\mathrm{K}, \mathbf{R b}, \mathbf{C s}$, $\mathrm{Sr}$ and $\mathrm{Ba}$ between clinopyroxene and liquid at high pressures, Geochim. Cosmochim. Acta, 38, 1789-1798, 1974.

Shimizu, N., and I. Kushiro, The partition of rare earth elements between garnet and liquid at high pressures: Preliminary experiments, Geophys. Res. Lett., 2, 413-416, 1975.

Smith, J. V., Possible controls on the bulk composition of the earth: Implications for the origin of the earth and moon, Proc. Lunar Sci. Conf. 8th, 333-369, 1977.

Spooner, E. T. C., The strontium isotopic composition of seawater, and seawater-oceanic crust interaction, Earth Planet. Sci. Lett., 31, 167-174, 1976.

Sun, S. S., and R. W. Nesbitt, Chemical heterogeneity of the Archaen mantle, composition of the earth and mantle evolution, Earth Planet. Sci. Lett., 35, 429-448, 1977.

Tatsumoto, M., Isotopic composition of lead in oceanic basalt and its implication to mantle evolution, Earth Planet. Sci. Lett., 38, 63-87, 1978.

Taylor, S. R., Trace element abundances and the chondritic earth model, Geochim. Cosmochim. Acta, 28, 1989-1998, 1964.

Taylor, S. R., Island arc models and the composition of the continental crust, in Island Arcs, Deep Sea Trenches, and Back Arc Basins, edited by M. Talwani and W. Pitman, AGU, Washington, D. C., 1977.

Taylor, S. R., and A. J. R. White, Geochemistry of andesites and the growth of continents, Nature, 205, 271-273, 1965.

Tera, F., D. A. Papanastassiou, and G. J. Wasserburg, Isotopic evidence for a terminal lunar cataclysm, Earth Planet. Sci. Lett., 22, 121, 1974.

Wasserburg, G. J., Pb-U-Th evolution models for homogenous systems with transport (abstract), Eos Trans. AGU, 45, 111, 1964.

Wasserburg, G. J., Geochronology and isotopic data bearing on the development of the continental crust, in Advances in Earth Sciences, MIT Press, Cambridge, Mass., 1966.

Wasserburg, G. J., G. F. J. MacDonald, F. Hoyle, and W. A. Fowler Relative contributions of uranium, thorium and potassium to heat production in the earth, Science, 143, 465-467, 1964.

Weill, D. F., and G. A. McKay, The partitioning of Mg, Fe, Sr, Ce, $\mathrm{Sm}$, Eu and $\mathrm{Yb}$ in lunar igneous systems and a possible origin of Kreep by equilibrium partial melting, Proc. Lunar Sci. Conf. 6th, 1143-1158, 1975.

Veizer, J., and W. Compston, ${ }^{87} \mathrm{Sr} /{ }^{86} \mathrm{Sr}$ composition of seawater during the Phanerozoic, Geochim. Cosmochim. Acta, 38, 1461-1484, 1974.

Williams, D. L., and R. P. von Herzen, Heat loss from the earth; New estimate, Geology, 2, 327-328, 1975.

(Received May 22, 1979;

accepted August 14, 1979.) 